Final Technical Report

\title{
Evaluation and Characterization of In-Line Annealed Continuous Cast Aluminum Sheet DE-FC36-01ID14024
}

\author{
August 2005 \\ Principal Investigator: \\ Dr. Subodh K. Das \\ Secat, Inc. \\ Secat Inc \\ 1505 Bull Lea Road \\ Lexington KY 40511 \\ Tel: 8595144989 \\ Fax: 8595144988 \\ www.secat.net
}




\section{Final Technical Report}

Project Title:

Evaluation and Characterization of In-Line

Annealed Continuous Cast Aluminum Sheet

Award Number:

DE-FC36-01ID14024

Project Period:

February 2001 to December 2003

Recipient Organization: Secat, Inc.

PI:

Dr. Subodh K. Das

Additional Researchers:

Dr. B. Radhakrishnan (ORNL)

Dr. James G Morris (UK)

Dr. Xiyu Wen (UK)

Dr Amit Ghosh (University of Michigan)

Mr. Shridas Ningileri (Secat)

Dr. Zhong Li (Aleris International)

Paul Platek (Aleris International)

University:

University of Kentucky

University of Michigan

National Laboratories:

Oak Ridge National Laboratory

Industrial Partners:

Aleris International

(Previously Commonwealth Aluminum)

Ajax Magnethermic 


\section{Acknowledgments and Disclaimer}

\section{Acknowledgments}

This report is based upon work supported by the U.S. Department of Energy, Energy Efficiency and Renewable Energy, Industrial Technologies Program, Aluminum Industry of the Future, under Solicitation No. DE-PS07-99ID13824 with award made to Secat, Inc.

Research was sponsored by the U.S. Department of Energy, Office of Energy Efficiency and Renewable Energy, Industrial Technologies Program, under contract DE-AC05-00OR22725 with UT-Battelle, LLC.

The significant accomplishments of this project would not have been achieved without access to the excellent facilities of the Oak Ridge National Laboratory, Aleris International and Secat, Inc, made available through Peter Angelini, H. Wayne Hayden, Zhong Li, Paul Platek, and S.K. Das. The principal investigators of this project also realize that the significant accomplishments of this endeavor could not have been achieved except through the dedicated and excellent contributions of the other project research team members from the Oak Ridge National Laboratory, the University of Kentucky and the University of Michigan composed of B. Radhakrishnan, Amit Ghosh, Dr Morris, and Xiyu Wen.

\section{Disclaimer}

This report was prepared as an account of work sponsored by an agency of the United States Government. Neither the United States Government nor any agency thereof, nor any of their employees, makes any warranty, express or implied, or assumes any legal liability or responsibility for the accuracy, completeness, or usefulness of any information, apparatus, product, or process disclosed, or represents that its use would not infringe privately owned rights. References herein to any specific commercial product, process, or service by trade name, trademark, manufacturer, or otherwise, does not necessarily constitute or imply its endorsement, recommendation, or favoring by the United State Government or any agency thereof. The views and opinions of authors expressed herein do not necessarily state or reflect those of the United States Government or any agency thereof.

\section{Proprietary Information}

It is to be noted that the work was done with the cooperation of Aleris International and the major accomplishments of this project are tied in with several patents that the company intends to pursue on related subjects and results. Hence this report does not cover in detail the results of such work including process details and comparative data between $\mathrm{CC}$ and DC cast material except $\mathrm{t}$ state that the results prove that $\mathrm{CC}$ can make comparable or better material at lower cost. Data published in this report can be released to the public 


\section{Table of Content}

Table of Contents 4

Abbreviations and Acronyms 5

1. Executive Summary 6

1.1 Research and Development $\quad 6$

$\begin{array}{ll}1.2 \text { Technology Transfer } & 7\end{array}$

1.3 Commercialization $\quad 8$

1.4 Recommendations $\quad 8$

2. Introduction 9

3. Background 11

3.1 Project Goals and Scope $\quad 11$

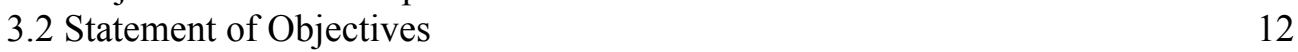

3.3 Work Breakdown Structure 12

4. In Line Anneal - Installation and Trials 14

$\begin{array}{ll}4.1 \text { Introduction } & 14\end{array}$

4.2 Design Installation and Trials - In Line Unit at Carson Facility 14

5. Material Characterization and Property Evaluation 15

$\begin{array}{ll}5.1 \text { Introduction } & 15\end{array}$

$\begin{array}{ll}5.2 \text { University of Michigan } & 15\end{array}$

5.2.1 Introduction $\quad 15$

5.2.2 Experimental 16

5.2.3 Results 17

5.2.4 Discussions 21

5.3 Oak ridge National Laboratory $\quad 22$

5.3.1 In Line Anneal 22

5.3.2 Optimization Modeling 27

5.3.3 Observations 38

5.4 University of Kentucky \& Secat Inc $\quad 38$

5.4.1 Introduction 38

5.4.2 Experimental Results $\quad 39$

5.4.3 Observations and Summary 40

6. Cost Analysis $\quad 40$

7. Accomplishments $\quad 40$

8 Summary and Conclusions $\quad 42$

9. References 43

10. Publications 44 


\section{Abbreviations and Acronyms}

ORNL

DOE

UK

IOF

ITP

SEM

TMS

$\mathrm{CC}$

DC
Oak Ridge National Laboratory

Department of Energy

The University of Kentucky

Industry of the Future

Industrial Technologies Program

Scanning Electron Microscopy

The Minerals, Metals, and Materials Society

Continuous Casting

Direct Chill Casting 


\section{Executive Summary}

\subsection{Research and Development}

This R\&D program will develop optimized, energy-efficient thermo-mechanical processing procedures for in-line annealing of continuously cast hot bands of two 5000 series aluminum alloys (5754 and 5052). The implementation of the R\&D will result in the production of sheet with improved formability at high levels of productivity consistency and quality.

The proposed R\&D involves the following efforts:

- Design and build continuous in-line annealing equipment for plant-scale trials.

- Carry out plant-scale trials at Commonwealth Aluminum Corp.'s (CAC) plant in Carson, California.

- Optimize the processing variables utilizing a metallurgical model for the kinetics of microstructure and texture evolution during thermo-mechanical processing.

- Determine the effects of processing variables on the microstructure, texture, mechanical properties, and formability of aluminum sheet.

- Develop design parameters for commercial implementation.

- Conduct techno-economic studies of the recommended process equipment to identify impacts on production costs.

The research and development is appropriate for the domestic industry as it will result in improved aluminum processing capabilities and thus lead to greater application of aluminum in various industries including the automotive market. A teaming approach is critical to the success of this effort as no single company alone possesses the breadth of technical and financial resources for successfully carrying out the effort. This program will enable more energy efficient aluminum sheet production technology, produce consistent high quality product, and have environmental benefits.

The proposal addresses the needs of the aluminum industry as stated in the aluminum industry roadmap by developing new and improved aluminum processes utilizing energy efficient techniques. The effort is primarily related to the subsection on Rolling and Extrusion with the $\mathrm{R} \& \mathrm{D}$ to address energy and environmental efficiencies in aluminum manufacturing and will provide significant energy, environmental and economic benefits thus benefiting a broad crosssection of the aluminum industry". The results from this project will have a positive impact on improving efficiencies in other areas of aluminum processing including Casting and in the Finished Products Sector of the roadmap

Continuous casting (CC) leads to $25 \%$ energy savings in the production of aluminum sheet products compared to conventional DC casting as it does away with the intermediate steps of DC cast ingots and homogenization of the ingots and substituting it with a continuous casting process which goes directly into the hot rolling mill. The results of the proposed research will enable further applications of continuous casting technology. The aim here is to develop a continuous in line anneal process that will replace the existing batch type techniques thereby resulting in a continuous uni-directional movement of material from cast to final product.

The goal of this multi-partner R\&D project is to develop energy-efficient and optimized thermomechanical processing for the production of continuous cast 5000 series aluminum sheet alloys. Full scale implementation of the proposed effort by the year 2015 could lead to yearly energy 
savings of 23 trillion Btu and related energy cost savings of $\$ 96$ million per year for the U. S. aluminum rolled products industry.

The major achievements of this project based on the goals and objectives of the project are given below.

\section{Design and build continuous in-line annealing equipment for plant-scale trials}

Prior to the project annealing was carried out as a batch type process. Based on process inputs from Aleris International CC facility and design by Ajax Magnethermic a continuous in line annealing equipment was designed and installed at Aleris International's Carson facility for carry out industrial size trails. This has resulted in knowledge on design and fabrication of in line annealing equipment for $\mathrm{CC}$.

Carry out plant-scale trials at Aleris International's facility in Carson, California.

Trials were carried out at the facility over a period of a week that was successfully able to produce in line annealed sheets for detailed material characterization and comparison of material properties vide the regular DC Casting process.

Optimize the processing variables utilizing a metallurgical model for the kinetics of microstructure and texture evolution during thermo-mechanical processing.

ORNL has carried out detailed work in the development of model that can be used to assist in predicting the kinetic of microstructure and texture evolution based on thermo mechanical processing. The model has been validated based on actual measurements carried out on material produced during the trials. The model is resident at Secat for use in interpretation of structures and its correlation to thermo mechanical processing steps.

Determine the effects of processing variables on the microstructure, texture, mechanical properties, and formability of aluminum sheet.

Detailed material characterization work was carried out with respect to tensile properties, formability, texture and microstructure. The studies proved that in line anneal can be utilized to produce sheet material with properties comparable to conventional CC cast products

Develop design parameters for commercial implementation.

Based on the successful conclusion of the trials design data has been generated that can be utilized for the construction of an inline anneal based plant either by retroactive fitment of the system or by the construction of a new plant at a Greenfield site.

Conduct techno-economic studies of the recommended process equipment to identify impacts on production costs.

Detailed techno-economic study has been carried out of the inline process as compared to existing process considering land, energy and capital investment. The savings are observed to be appreciable with respect to energy and hence cost/unit product produced.

Full scale implementation of the proposed effort by the year 2015 could lead to yearly energy savings of 23 trillion Btu and related energy cost savings of $\$ 96$ million per year for the U. S. aluminum rolled products industry.

\subsection{Technology Transfer}

Intellectual property has been generated from this significant research effort. The intellectual property includes: (1) the predictive microstructure model that can be used to assist in predicting microstructure behavior as related to different thermo mechanical processing techniques that is 
resident at Secat, Inc. and at ORNL and are accessible to the aluminum industry (2) Specific material property data on in line annealed material that is proprietary to Aleris International on $5 \mathrm{xxx}$ aluminum alloys (3) design data on in line anneal equipment. University of Kentucky and Secat research staff members have actively participated in the evaluation of material properties utilized in the the modeling effort throughout the project period.

The basic model is available for use by the entire aluminum industry.

\subsection{Commercialization}

The project being proprietary in nature has resulted in information that can be used to set up a plant with low cost/unit product by Aleris International or licensed appropriately. Several patents are being processed in the regard by the industry partner in order to protect the relevant information.

\subsection{Recommendations}

This research project has successfully demonstrated that the use of in line anneal in the continuous casting process can result in large savings in energy. Based on capital cost investment the industrial partner has to decide on an opportune time for making the necessary capital investments. 


\section{Introduction}

The Hazelett belt casting technology has been commercialized for large tonnage production of aluminum sheet [i] and has been used by Commonwealth Aluminum Corp (CAC) to produce low cost aluminum sheet for a broad range of applications. Although the Hazzlett technology provides a commercially viable route for producing sheet products for a broad range of applications, significant technical challenges remain to be solved before it can be used to feed the high-volume automotive market.

Recently [ii], the feasibility of using automotive applications of continuously cast aluminum alloy AA5754 sheet products was studied through a DOE-funded R\&D project. Although AA5754 sheet with sufficient formability for stamping a dash panel pan was produced, it was not established that the process could be used for producing sheet that consistently met or exceeded the properties of conventionally processed sheet. This proposal goes beyond the previous work by the development and testing of a pilot scale on line annealing system. Results of the current proposal will provide a clear commercialization path in utilizing energy efficiency in live annealing.

The fabrication of complex automotive parts by stamping imposes stringent requirements for formability. Enhanced formability appears to require optimization of both the microstructure and texture in addition to meeting strength requirements. Based on the experience gained in the conventional processing of DC ingots one of the requirements for achieving this goal appears to be the realization of a consistent hot band microstructure and micro texture through complete recrystallization. Efforts have been underway at CAC to develop procedures for in-line annealing of hot band prior to coiling so that additional downstream annealing of the coil prior to re-rolling can be avoided. The major objective of the proposed R\&D is to optimize the design of an in-line annealing facility so that complete recrystallization can be obtained consistently in the hot bands of 5000 series alloys.

The proposed R\&D will be conducted by a team consisting of the industry (SECAT, CAC and AJAX), national laboratory (ORNL) and academia (University of Kentucky and University of Michigan). CAC has been working on the development of continuous in-line anneal of continuous cast aluminum alloy sheet for many years. The industry will participate by installing the continuous annealing facility developed under this project in one of their production facilities, performing controlled runs using the thermo-mechanical processing and annealing cycles proposed by the R\&D team and providing samples for characterization and formability studies. The industry representatives will also provide the overall guidance and direction to the project through active participation in identifying and monitoring project deliverables and technical progress. The national laboratory and the member universities will conduct the bulk of the R\&D.

The 5000 series alloys are non-heat-treatable, and the strength and formability requirements are essentially met through grain size control and solid solution strengthening due to the presence of $\mathrm{Mg}$ in solution. Automotive sheet is generally supplied in the $\mathrm{O}$ temper where the final processing step involves the cold rolling and annealing of the hot band. The final grain size varies inversely with the amount of cold reduction prior to annealing. The microstructural variables that control recrystallization are the volume fraction, size, and spatial distribution of dispersoids in the hot band. These variables also influence the anisotropy factor, $r$, which controls formability. The presence of $\mathrm{Mg}$ in solid solution also causes an increase in the strain- hardening coefficient, which results in increased formability.

Associated with the near-net processing technology are the new sets of solidification and thermomechanical processing variables that are drastically different from that of conventional processing. 
While conventional material is homogenized and thermo-mechanically processed in a roughing mill before undergoing hot rolling in multi-stand mills, Hazelett-cast material is directly finishhot-rolled with no homogenization treatments. A possible microstructural issue in continuously cast hot-band is the presence of solidification-induced solute segregation. A major objective of this proposal is to minimize the influence of microstructural variabilities in the cast material on the hot band properties so that the properties of the final sheet are consistent. The introduction of in-line heating prior to coiling the hot band product is proposed as a method for ensuring complete recrystallization and the development of optimum texture with minimal throughthickness variability.

Although different aspects of the DC-casting startup phase have been addressed in literature [1-10, 12-15], there are no previous studies that combine fluid flow, solidification, microstructure evolution, strain-stress development, and crack formation. Schneider and coworkers [1-3] carried out experimental investigations on the effect of process parameters on cracking tendency. Mortensen [4] developed a detailed model of the heat and fluid flow patterns during DC casting. Wiskel and Cockcroft $[5,6]$ carried out a heat flow-based analysis of surface crack formation during the start-up phase of the DC casting process. Mathew and Brody [7], Hannart et al. [8], Fjaer and Mo [9], and Drezet and Rappaz [10] all developed models to predict the stresses, strains, and distortions that develop during DC casting. These studies, in particular those of Fjaer and Mo [9] and Drezet and Rappaz [10], are very comprehensive and calculate the thermally induced stresses and strains and distortion during DC casting and treat the metal as an elastic viscoplastic material with temperature-dependent properties.

The project was funded by DOE under the aluminum Industry of the Future Program. The goal of the project was to assist the aluminum industry to reduce the incident of stress cracks from a current level of 5\% down to 2\%. The research covered the following aspects: (1) Model geometry - Due to the non-uniformity in the ingot geometry and cooling conditions, the computational geometry must be three-dimensional. (2) Thermal boundary conditions - In order to accurately predict the stress and strain fields in regions prone to crack formation, the heat transfer model must take into account the various regimes of heat transfer between the ingot and the mold, the bottom block, and the cooling water. (3) Crack formation - The nature of face crack were not well known. These cracks are often seen in the central region of the rolling face of the DC ingot. Criteria for crack formation have to be developed. (4) Effect of solidification microstructure Microstructures of alloys in the as-cast conditions are usually inhomogeneous and contain multiple phases. In such complex microstructures, the microstructural geometry and distribution of length scales can have a profound effect on the initiation of fracture and the fracture path. (5) Computational approach - Models for the prediction of cracking formation have to account for elastic, thermal, and inelastic effect as well as the combined effects of fluid convection, heat transfer, solidification, microstructural evolution, and stress and strain generation in DC casting.

The energy and cost savings and the environmental impact of this project are significant. The U.S. aluminum industry produces 20 billion lbs of aluminum annually [16]. Assuming the melt loss of aluminum is $4 \%$, a scrap rate reduction from $5 \%$ to $2 \%$ could lead to an energy saving of 7 trillion Btu, and a cost saving of $\$ 37$ million by the year 2025 . These energy and cost savings were estimated using the ITP spreadsheet under assumptions that an annual growth of aluminum production is $2 \%$ and the market share of the project results is $100 \%$. 


\section{Background}

\subsection{Project Goal and Scope}

The goal of the project is to optimize the material and thermo-mechanical processing variables in the continuous casting of 5000 aluminum alloy sheet so that the product meets the formability requirements for automotive applications. This will be accomplished by carefully designed parametric tests conducted at the industrial facility, and assessing the microstructural and mechanical behavior of the output material. Process optimization will be carried through fundamental understanding of the evolution of microstructure and texture that occur during solidification, deformation and recrystallization. This goal will be achieved through a collaborative research program involving the aluminum industry, national laboratory and the academia. The program will build on the significant expertise that the R\&D team already possesses in industrial thermal processing, advanced characterization of microstructure and material formability and fundamental understanding of the metallurgical principles involved in industrial thermo-mechanical processing of aluminum alloys.

\section{Plant Scale Trials}

Plant-scale pilot in-line induction annealing equipment will be designed and installed at the CAC, Carson, CA plant. In-plant tests using the equipment described in the above section will be will be conducted on aluminum alloys AA 5754 and AA 5052 at the Commonwealth Aluminum plant in Carson California.

The set of process variables for material in any given coil will be maintained for the production of the bulk of that coil. A portion of the material from heavier gage coils will be cold rolled to final gage thickness. Material from cold rolling trials will be evaluated in both the annealed condition.

\section{Material Characterization and Evaluation of Properties}

The objective of the characterization effort is to establish quantifiable relationships between key thermo-mechanical processing variables, the microstructure of the hot band as well as the microstructure of sheet produced by cold rolling and annealing. This will be done utilizing the facilities available at ORNL, University of Kentucky and Secat Inc

Mechanical characterization of the hot band and cold rolled sheet products will be performed. Mechanical characterization will include uniaxial tensile tests and cup deep drawing (or limiting dome height) tests will be performed on hot band and cold rolled and annealed material. This will be done utilizing the facilities available at ORNL, University of Kentucky and Secat Inc

\section{Process Optimization Modeling:}

The overall objective of the optimization modeling is to relate the mill practice to the material variables so that the overall process can be optimized to achieve the desired microstructure in the hot band.

The focus will be to utilize a process optimization model and understand of the evolution of microstructure and microtexture in the hot band as a function of the initial Hazelett-cast microstructure, hot-rolling schedule, rolling speed, temperature, inter-pass time, strain, strain rate and in-line annealing conditions. As described previously, one of the important variables in continuously cast microstructures is the variation in local composition due to solute segregation and deformation gradients that may have significant impact on local recrystallization kinetics, 
microstructure and microtexture. The kinetics of the above metallurgical processes will be quantitatively studied using some of the unique predictive tools developed at ORNL [iii, iv].

\section{Cost Analyses:}

The techno-economic evaluation for the impact of the proposed in-line annealing process on the costs for the production of continuously cast sheet products of AA 5754 and AA 5052 is carried out by H Wayne Hayden, consultant. The study will be based on models that CRA has employed for evaluations of production process technologies. The studies will include estimation of capital costs for the equipment and production costs including labor, utilities, maintenance, interest and amortization costs.

\subsection{Statement of Objectives}

The objective of the proposed $\mathrm{R} \& \mathrm{D}$ is to develop energy-efficient and optimized material and thermo-mechanical processing variables in the production of continuously cast hot bands of 5000 series aluminum alloys (5754 and 5052) such that the formability of the final cold rolled and annealed sheet can be enhanced to meet automotive requirements. This objective will be accomplished by conducting a set of tasks designed to provide insights into the basic mechanisms of microstructure and texture evolution in the hot band which, in turn, will be used to design inline heating and other suitable modifications to the process.

\subsection{Work Breakdown Structure}

The following tasks have been envisioned to meet the overall objective of the proposed R\&D.

Task 1: In-line Annealing: The focus of this task is to design, build, install and evaluate a pilotscale in-line annealing equipment using induction heating technology. Ajax Magnethermic will have the prime responsibility for this task. The pilot facility will be installed at the continuous casting facility at Carson, California that has the capacity to produce 22 " wide sheet. The design will be based on inputs generated by the research team on thermophysical properties of 5052 and 5754, metallurgical process modeling, and thermal modeling based on Ajax's in-house computing capabilities. The following sub-tasks have been envisioned:

1.1 Experimental determination of thermo-physical properties (electrical resistivity, heat capacity) of AA5052 and AA5754 (UK)

1.2 Predict heating requirements using inputs from 1.1 and mill parameters, predict temperature profiles (Ajax)

1.3 Metallurgical process modeling of recrystallization using input from 1.2 (ORNL)

1.4 Design, fabricate and install pilot facility at Carson, $\mathrm{Ca}$ and evaluate performance (Ajax, CAC)

1.5 Design, build and evaluate laboratory scale infrared heating facility.

1.6 Optimize heating conditions to achieve the desired heating rates in sample gauges of interest sample gauges provided by the industrial partner.

Task 2: In-plant Trials: The objective of this task is to conduct parameteric studies of the influence of in-line annealing and mill parameters on the properties of the hot band. Ajax and $\mathrm{CAC}$ will be primarily responsible for this task. The process parameters include line speed, sheet thickness and in-line annealing power. Additional variable that will be measured using a noncontact infra red camera is the temperature profile across the sheet width. This subtask will be 
carried out by ORNL. Any variability in property obtained by characterizing the hot-band will be correlated with the above process parameters. The following subtasks have been envisioned:

2.1 Influence of sheet thickness (ranging from 0.40 " to 0.120 "

2.2 Influence of annealing power (sheet temperature)

2.3 Influence of line speed (ranging from 23 to $34 \mathrm{ft} / \mathrm{min}$ )

2.4 Influence of temperature variability

Task 3: Optimization Modeling: The goal of this task is to develop a fundamental understanding of the influence of material variables and thermo-mechanical processing variables on the evolution of microstructure and texture in the hot band. ORNL will have the prime responsibility for this task. The following subtasks have been envisioned:

3.1 Calculate through-thickness deformation history during a typical rolling schedule.

3.2 Knowing the initial microstructure, texture and thermo-mechanical history, calculate the final microstructure and microtexture after hot rolling. Compare with experimental measurements.

3.3 Determine the influence of local composition variation on recrystallization kinetics.

3.4 Use fundamental information gained from 3.2 and 3.3 to optimize in-line heating requirements to obtain the desired properties in the hot band

Task 4: Material Characterization: This task includes both microstructural and mechanical characterization of the hot band and sheet processed using in-line annealing technology. The objective of the characterization task is to provide data that can be used for the design, development and optimization of alloy processing parameters. The data will also be used for validating process optimization models. The following subtasks have been envisioned:

4.1 Characterize the grain size, shape, grain size distribution, size and volume fraction of second phases using optical metallography (UTK)

4.2 Micro-texture and texture gradient characterization using EBSP (ORNL)

4.3 Monotonic uniaxial testing to measure yield strength, and ultimate strength, work hardening exponent and strain at failure (ORNL).

4.4 Conduct deep drawing tests using a servo-hydraulic testing machine with a wide range of strain rate capabilities (ORNL).

4.5 Determine in-plane biaxial strain hardening and fracture strain (UM)

4.6 Determine strain hardening in shear (UM)

4.7 Determine strain hardening behavior under uniaxial tension after biaxial prestrain (UM)

Task 5: Cost Analysis

The studies will include estimation of capital costs for the equipment and production costs including labor, utilities, maintenance, interest and amortization costs.

Task 5: Final Report 


\section{In Line Anneal - Installation and Trials}

\subsection{Introduction}

The 5000 series alloys are non-heat-treatable, and the strength and formability requirements are essentially met through grain size control and solid solution strengthening due to the presence of $\mathrm{Mg}$ in solution. Automotive sheet is generally supplied in the $\mathrm{O}$ temper where the final processing step involves the cold rolling and annealing of the hot band. The final grain size varies inversely with the amount of cold reduction prior to annealing. The microstructural variables that control recrystallization are the volume fraction, size, and spatial distribution of dispersoids in the hot band. These variables also influence the anisotropy factor, $r$, which controls formability. The presence of $\mathrm{Mg}$ in solid solution also causes an increase in the strain- hardening coefficient, which results in increased formability.

Associated with the near-net processing technology are the new sets of solidification and thermomechanical processing variables that are drastically different from that of conventional processing. While conventional material is homogenized and thermo-mechanically processed in a roughing mill before undergoing hot rolling in multi-stand mills, Hazelett-cast material is directly finishhot-rolled with no homogenization treatments. A possible microstructural issue in continuously cast hot-band is the presence of solidification-induced solute segregation. A major objective of this proposal is to minimize the influence of microstructural variabilities in the cast material on the hot band properties so that the properties of the final sheet are consistent. The introduction of in-line heating prior to coiling the hot band product is proposed as a method for ensuring complete recrystallization and the development of optimum texture with minimal throughthickness variability.

In the proposed $R \& D$, induction heating has been chosen as the candidate technology for rapid heating based on its proven performance in the steel industry. Infrared heating will also be considered as an alternative or augmentation system, if its feasibility can be clearly established. The amount of heat to the aluminum strip will be optimized such that complete recrystallization will occur without causing significant grain growth in the hot band. Ajax Magnethermic will use published and experimental data on alloy electrical resistivity with their proprietary models for developing the design of the proposed plant-scale test induction heating equipment. In support of our concept of performing a pilot scale in-line annealing effort, the equipment will be constructed and installed at CAC's Carson, California plant. Tests for the production of sheet products will be conducted using the pilot equipment. Results from the test runs will be used for designing permanent production in-line annealing equipment.

\section{2: Design, Installation and Trials of In-Line unit at the Carson Facility}

A visit was made by the project team to the Aleris facilities at Newport and Carson to understand the working of the Hazelett Mill and the operational conditions of the unit. Due to size and operational convenience the it was decided to design the unit for the Carson facility taking into account the speed of the hot rolling operations, process temperatures and the time required to carry out the flash anneal using the IR facility prior to cooling and rolling.

Drawings and design details of the proposed in-line annealing unit were discussed at project review meetings subsequently and it was decided that the unit will be 72" long to keep the current density at a reasonable level and will have capacitor banks on both sides, not a very common feature. Conveyor belts will be used to guide the strip into the narrow gap between the coils. Design work on the heating unit was completed by end 2001. Engineers from Commonwealth and Ajax visited the Carson facility to define the logistics and plant floor changes required for 
installation and based on installation schedules and operational convenience the trials were carried out in May 2002.

Two alloys of different gauges were in-line annealed at different temperatures and coil samples were made and collected for comparison of properties with normally processed material as well onal temperature maps of the ingot surface. Figure 4.5 shows an IR image of the ingot surface just below the mold. The IR image was taken at the start of the cast. The bottom part of the image shows the bottom block as indicated in the figure. It can be seen that the temperature of the bottom block is lower than $100{ }^{\circ} \mathrm{C}$, which is much lower than that of the ingot surface. The ingot surface temperature is about $500{ }^{\circ} \mathrm{C}$, suggesting the heat transfer there is in the film boiling mode. It can be seen that the isothermal lines are nearly horizontal, indicating that $2 \mathrm{D}$ simulation is applicable to this case.

\section{Material Characterization and Property Evaluation}

\section{1: Introduction}

The work carried out on material characterization and property evaluation was carried out at four sites consisting of the University of Michigan, The University of Kentucky, Secat Inc and Oak Ridge National Laboratory with supportive work carried out at the laboratories of Aleris International.

The division of the work carried out at the four sites is as follows.

- University of Kentucky/Secat Inc: Determination of texture and mechanical properties of continuously cast AA5754 Al Alloy as a function of cold rolling and annealing parameters

- University of Michigan: Determine the formability of continuously cast AA5052 alloys as a function of cold rolling and annealing parameters.

- Oak Ridge National Laboratory: (1) Advanced characterization of the AA5052 and AA5754 hot bands using EBSP technique to determine the microtexture and its variation through the thickness of the sheet (2) Determine the high temperature mechanical properties of AA5754 hot band to provide input for modeling the deformation behavior of the alloy during hot rolling (3) Develop techniques for providing laboratory samples of rapidly annealed hot band for formability studies (4) Model the microstructure evolution during in-line recrystallization of hot band.

The details of work carried out at these locations are given in detail below.

\section{2: University of Michigan}

\subsection{1: Introduction}

The process of continuous casting of metals generally combines with it a hot rolling operation used to produce Al plates and sheets for industrial application. In conventional sheet manufacture, cold rolling from plate with annealing is generally used to develop recrystallized grain structure. Thin sheets produced by continuous casting process have economic advantage over conventionally produced thin sheets. However, no information exists on the effect of cold rolling on continuously cast plates. The cold rolling and annealing heat treatment may change the 
crystallite orientations, mechanical properties and formability of thin sheet. The formability of sheet metal is characterized by its forming limit curves. Forming limit behavior of these materials under biaxial stretching condition has not been explored previously. In the beginning of the inline annealing project, a study was performed to determine the role of cold rolling and annealing process on the properties of continuous cast and hot rolled $5052 \mathrm{Al}$ sheet in order to determine if it would be of value to continue to roll the sheets further beyond the hot rolling strand before passing through an in-line annealing operation. Thus while the continuous cast sheets are typically finished in hot rolled or warm rolled condition, the purpose of this part of the study was to determine if cold rolled and annealed finish could improve the formability of the alloy. In this work, the mechanical properties, microstructures, textures and FLCs (Forming limit curves) have been evaluated to 5052 sheets with thickness of 0.063 " obtained by two processes. For this part of the work, the continuous cast and hot rolled sheet was referred to the as-received sheet. The other is obtained by cold rolling and annealing from a thicker plate produced by continuous casting and hot rolling. This sheet was referred to as the lab-processed sheet. The mechanical properties, microstructures, textures and FLCs of lab-processed sheets are compared to those of as-received sheets.

For the first part of the study, the tensile properties, microstructures, textures and Forming Limit Diagrams of $5052 \mathrm{Al}$ sheets, 0.063" thick, from the two different process schedules were examined. One of these was as-received continuous cast sheet provided in hot rolled condition. The other was produced in the laboratory by cold rolling from a $0.125^{\prime \prime}$ thick sheet received from continuous cast and hot rolled condition. This sheet is referred to as the lab-processed sheet. Cold rolling and annealing steps were found to improve the tensile elongation and the values of $\mathrm{n}$ and $\mathrm{R}$ compared to the values for the as-received sheet. With increase in rolling reduction during cold rolling followed by annealing, shows that the laboratory cold rolling process produces more random distribution of crystalline orientations and minimizes the intensity of cube component. The lab-processed sheet has better stretch ability than the as-received sheet

\subsection{2: Experimental}

Tensile specimens of size ASTM E8 (gauge length $=50.8 \mathrm{~mm}$ ) were cut along rolling direction and transverse direction. Then, all the tensile test specimens were annealed at $400^{\circ} \mathrm{C}$ for $90 \mathrm{~min}$, and air-cooled. This treatment was previously found to produce the lowest yield strength in the alloy, indicative of recrystallization-annealed condition. Uniaxial tensile tests were carried out in 5505 Instron tensile test instrument with crosshead velocity of $1 \mathrm{~mm} / \mathrm{min}$ and an extensometer with a gauge length of $50.8 \mathrm{~mm}$. The samples for optical microscopy were aged at $160^{\circ} \mathrm{C}$ for $15 \mathrm{~h}$ after annealing treatment to cause precipitation to decorate the grain boundaries. The specimens were etched with Killer's reagent, and microstructures in the center and near the surface in the thickness direction of sheets were observed in Olympus PME3 optical microscopy.

Plastic anisotropy of the sheets are a direct reflection of crystallographic texture and is indicative of sheet drawability. This parameter, $R$, is defined as the ratio of width strain to thickness strain in the tensile specimen was determined from measurements of these strains from the tested specimens. It is defined as

$$
R=\frac{\varepsilon_{w}}{\varepsilon_{t}}
$$

where $\mathrm{w}$ and $\mathrm{t}$ refer to the width and thickness direction of the tensile specimen. Thus, $\varepsilon_{w}=\ln \left(w / w_{0}\right)$ and $\varepsilon_{t}=\ln \left(t / t_{0}\right)$. However, because thickness strain, $\varepsilon_{t}$, cannot be accurately measured in a thin sheet, it is obtained from measurements of length and width strains far from 
the neck region, using volume constancy, $\varepsilon_{t}=-\left(\varepsilon_{l} / \varepsilon_{w}\right)$. The length strain, $\varepsilon_{l}$, can be obtained from $\varepsilon_{l}=\ln \left(1+\varepsilon_{E}\right)$, where $\varepsilon_{\mathrm{E}}$ is the uniform strain.

The curves of engineering stress vs. engineering strain, true stress vs. strain were plotted using Kaleidagraph software. The values of strain hardening exponent, $n$, could be determined from the slope of the logarithmic plot of true stress vs. true strain. These plots exhibited two stage hardening behavior. The value of strength coefficient, $\mathrm{K}$, is equal to the value of $\sigma$ for $\varepsilon=1.0$. These values were determined from each of the two segments of the curve.

Crystallographic textures were examined by determining the X-ray pole figures of (111) and (200) poles from both as received sheet and lab-processed sheet using Computerized Rigaku diffraction system. It consists of a $12 \mathrm{~kW}$ high intensity rotating anode X-ray generator with a horizontal goniometer for powder work and a second goniometer with a pole figure attachment. 3/4" square specimens were cut from these sheets and annealed at $400^{\circ} \mathrm{C}$ for $90 \mathrm{~min}$ for pole figure work. Then, the surfaces of specimens were polished in $120^{\#}$ sand paper and cleaned by acetone. The Xray equipment was conducted with $40 \mathrm{kV}$ voltage and $100 \mathrm{~mA}$ current.

\subsection{3: Results}

Mechanical properties - Table 1 summarizes the various mechanical properties of initial $5052 \mathrm{Al}$ sheet. These materials retained some amount of cold work as evidenced from their high yield strength of $265 \mathrm{MPa}$, and low elongation in the vicinity of 6-7\%. It can be found that all values of sheet with thickness of 0.125 " are somewhat higher than that of sheet with thickness of 0.063 " except for the value of $\mathrm{R}$. The unusually low $\mathrm{R}$ values $(\sim 0.2)$ of these materials appear to be a consequence of hot rolling after continuous casting.

\begin{tabular}{|c|c|c|c|c|c|c|c|}
\hline Material & Test Direction & $\begin{array}{c}\text { YS } \\
(\mathrm{MPa})\end{array}$ & $\begin{array}{c}\text { UTS } \\
(\mathrm{MPa})\end{array}$ & $\begin{array}{c}\text { El } \\
(\%)\end{array}$ & $\begin{array}{c}\mathrm{n} \\
(\mathrm{MPa})\end{array}$ & $\mathrm{R}$ \\
\hline As-received, $(0.125 "$ thk) & R.D. & 264.5 & 328.0 & 6.8 & 0.04 & 323.1 & 0.245 \\
\hline As-received, (0.063" thk) & R.D. & 266.1 & 336.8 & 7.7 & 0.05 & 334.3 & 0.187 \\
\hline
\end{tabular}

Table 1: Mechanical properties - $5052 \mathrm{Al}$ initial sheet produced by continuous casting $\&$ hot roll

Table 2 shows mechanical properties of as received sheet and lab-processed sheet after annealing at $400^{\circ} \mathrm{C}$ for $90 \mathrm{~min}$. After annealing, the strength is reduced and elongation increased. For the as-received sheet, the strength in rolling direction is slight lower, and the elongation and $\mathrm{n}$ values are higher than that in transverse direction. However, the value of $\mathrm{R}$ is higher $(>0.8)$ for transverse direction. For the lab-processed sheet with thickness of 0.063 ", both yield strength and elongation values in transverse direction are higher than that in rolling direction. 


\begin{tabular}{|l|l|l|l|c|c|c|c|c|c|c|}
\hline \multicolumn{2}{|c|}{ Material } & $\begin{array}{c}\text { YS } \\
(\mathrm{MPa})\end{array}$ & $\begin{array}{c}\text { UTS } \\
(\mathrm{MPa})\end{array}$ & $\begin{array}{c}\text { El } \\
(\%)\end{array}$ & $\begin{array}{c}\mathrm{n}_{1} \\
\mathrm{~K}_{1}\end{array}$ & $\begin{array}{c}\mathrm{n}_{2} \\
(\mathrm{MPa})\end{array}$ & $\begin{array}{c}\mathrm{K}_{2} \\
(\mathrm{MPa})\end{array}$ & $\varepsilon^{*}$ & $\mathrm{R}$ \\
\hline $\begin{array}{l}\text { As-received } \\
(0.063 " \text { thk })\end{array}$ & R.D. & 98.1 & 222.6 & 22.1 & 0.332 & 495.6 & 0.193 & 370.5 & 0.1266 & 0.62 \\
\cline { 2 - 12 } & T.D. & 98.7 & 224 & 21.3 & 0.325 & 495.6 & 0.183 & 358 & 0.1004 & 0.86 \\
\hline $\begin{array}{l}\text { Laboratory } \\
\text { TMT }(0.063 " \text { thk })\end{array}$ & R.D. & 102.1 & 215.1 & 21.1 & 0.312 & 455 & 0.2 & 358 & 0.12 & 0.68 \\
\cline { 2 - 12 } & T.D. & 108.4 & 225.9 & 27.1 & 0.325 & 470.8 & 0.253 & 410.6 & 0.1373 & 0.64 \\
\hline $\begin{array}{l}\text { Laboratory TMT } \\
(0.030 " \text { thk })\end{array}$ & R.D. & 97.88 & 217.3 & 20 & 0.338 & 517.9 & 0.192 & 362 & 0.0986 & 0.78 \\
\cline { 2 - 11 } & T.D. & & & & & & & & & \\
\hline
\end{tabular}

Table 2: Mechanical properties - $5052 \mathrm{Al}$ produced by continuous casting -anneal $400^{\circ} \mathrm{C} \mathrm{x} 90 \mathrm{~min}$

It was also found that for the sheet cold rolled to $0.030^{\prime \prime}$ (from $0.125^{\prime \prime}$ ), the mechanical properties were inferior compared to the properties of the 0.063 " thick sheet, except for its higher R value. All of these materials exhibited a two-stage n-value behavior, and typically the 0.063 " thick labprocessed material maintained a high $\mathrm{n}_{2}$ value. The stresses are a little bit higher in rolling direction than that in transverse direction at the same strain levels for as received sheet. However, the stresses are much higher in transverse direction than that in rolling direction for laboratory processed sheet.

Microstructure - The microstructures of sheet cross-section containing the thickness direction and the rolling direction of both the as received specimens and laboratory processed specimen, from the center and surface of specimen are shown in Fig.5 and Fig.6. The grains near the surface are finer than that in the center for both specimens. In as received specimens, from near surface to center, the grain length reduces from $74.5 \mu \mathrm{m}$ to $47 \mu \mathrm{m}$, and the grain thickness from $2.65 \mu \mathrm{m}$ to $1.57 \mu \mathrm{m}$. The grains in laboratory processed sheet are finer than that in same sections of as received sheet. The coarse grains in as-received sheet may be responsible for lower $\mathrm{n}_{2}$ value and higher R-value compared to laboratory processed sheet.

Texture - Crystallographic textures were examined by determining the X-ray (111) and (200) pole figures, shown in Fig.1, Fig.2 and Fig.3 for as received sheet, laboratory processed sheet with thickness of $0.063 "$ and 0.03", respectively. The pole figures indicate a mixture of deformation and annealing textures. The pole intensities in the peak regions for (111) are around 3 times random for all sheets. However, the pole intensities in the peak regions for (200) are around 6-8 times random for as received sheet, 4-6 times random for laboratory processed sheet with thickness of $0.063 "$, and 3-4 times random for laboratory processed sheet with thickness of $0.03 "$. These results show that the laboratory cold rolling process reduces the fraction of cube texture, which may be related to its higher $\mathrm{R}$ value. 


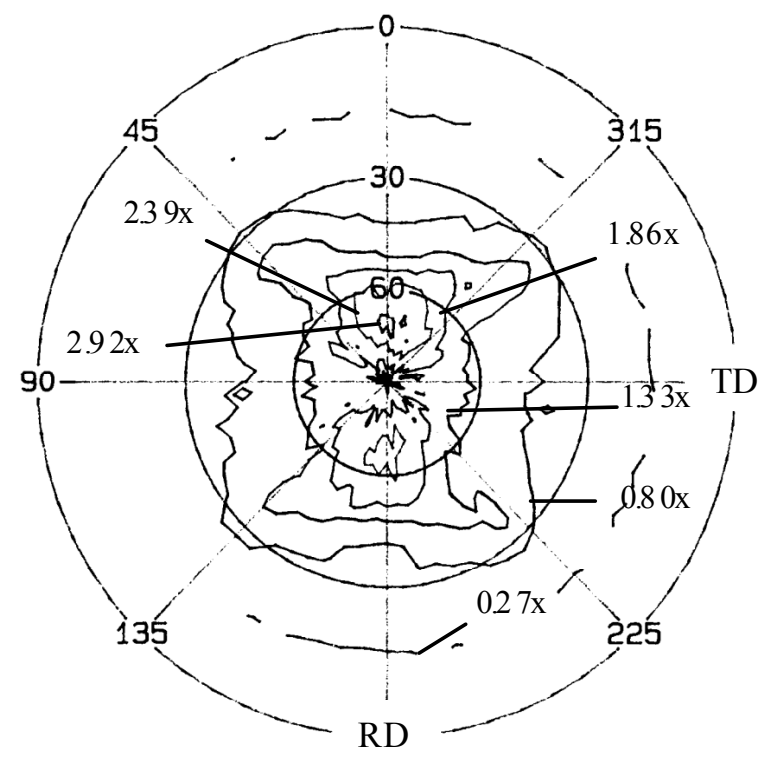

(a) (111)

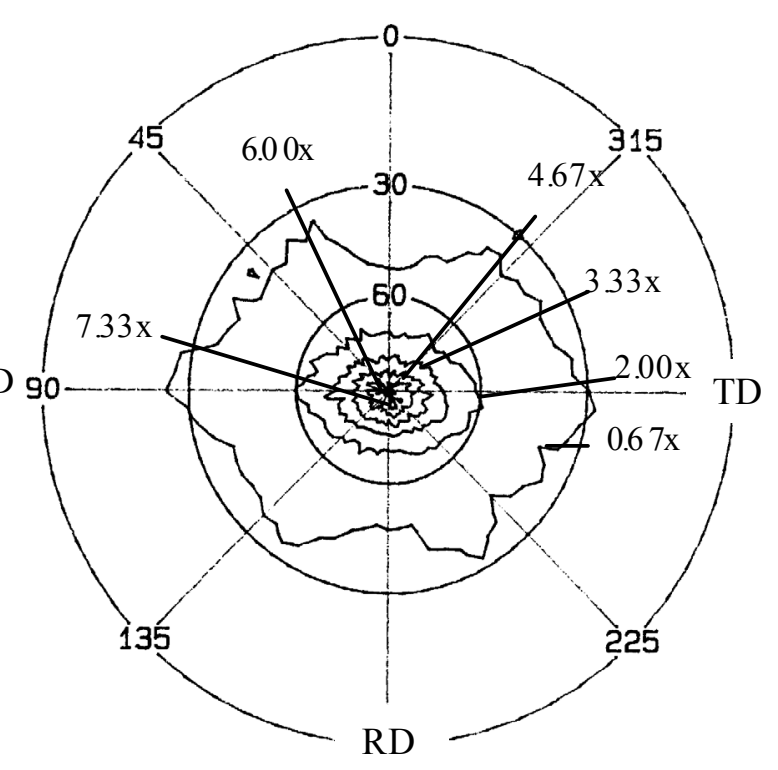

(b) (200)

Fig. $1 \mathrm{X}$-ray pole figures of 5052 aluminum sheet, as-received, 0.063" thick (Annealed at $400^{\circ} \mathrm{C}$ for $90 \mathrm{~min}$ )

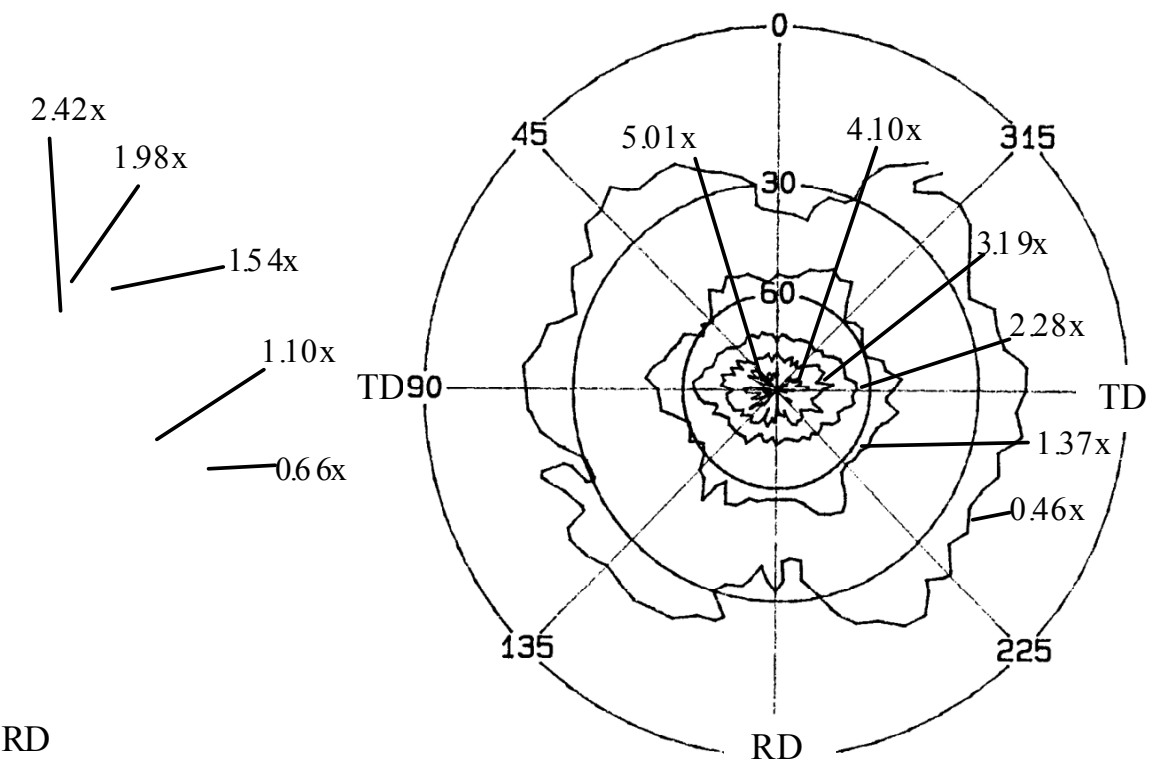

(a) (111)

(b) (200)

Fig. 2 X-ray pole figures of 5052 aluminum sheet (C.C.), lab processed, 0.063" thick (Cold rolled from $0.125^{\prime \prime}$ thk and annealed at $400^{\circ} \mathrm{C} / 90 \mathrm{~min}$ ) 


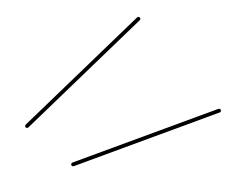

TD

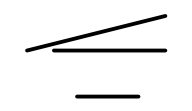

$\mathrm{RD}$

(a) (111)

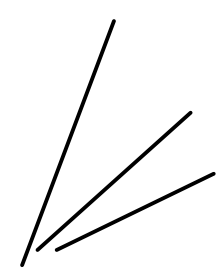

TD

$\mathrm{RD}$

(b) (200)

Fig 3: X-ray pole figures of 5052 aluminum sheet (C.C.), lab processed, $0.030 "$ thick (Cold rolled from $0.125^{\prime \prime}$ thk. and annealed at $400^{\circ} \mathrm{C} / 90 \mathrm{~min}$ )

Formability - Basically, formability is influenced by two things: flow behavior as determined by the stress-strain properties and fracture behavior as determined by the particles and their debonding within the material. The former determines a tendency for necking, while the latter determines the fracture strain, a critical factor for the biaxial strain limit. SEM studies taken some distance from the fracture region shows that cavity forms by decohesion from particles, so one needs to be careful about too high a temperature for annealing because particles may coarsen. On the other hand, there is always variation in particle size distribution from one region of the material to another and thus fracture strain may have greater variability.

A representative forming limit diagram is shown in Fig. 4. Annealing improves formability over the hot band material, but too high a temperature of annealing does not help. To show this behavior, the biaxial fracture strain is plotted as a function of annealing temperature. (Fig. 5) The effect is seen more clearly for fracture strain results under biaxial tension.

Because of the small difference in the forming limit for the lower annealing temperatures, it is believed that variations in the type of recrystallization may not play a big role on formability as long as recovery and recrystallization effects have removed the cold work sufficiently 


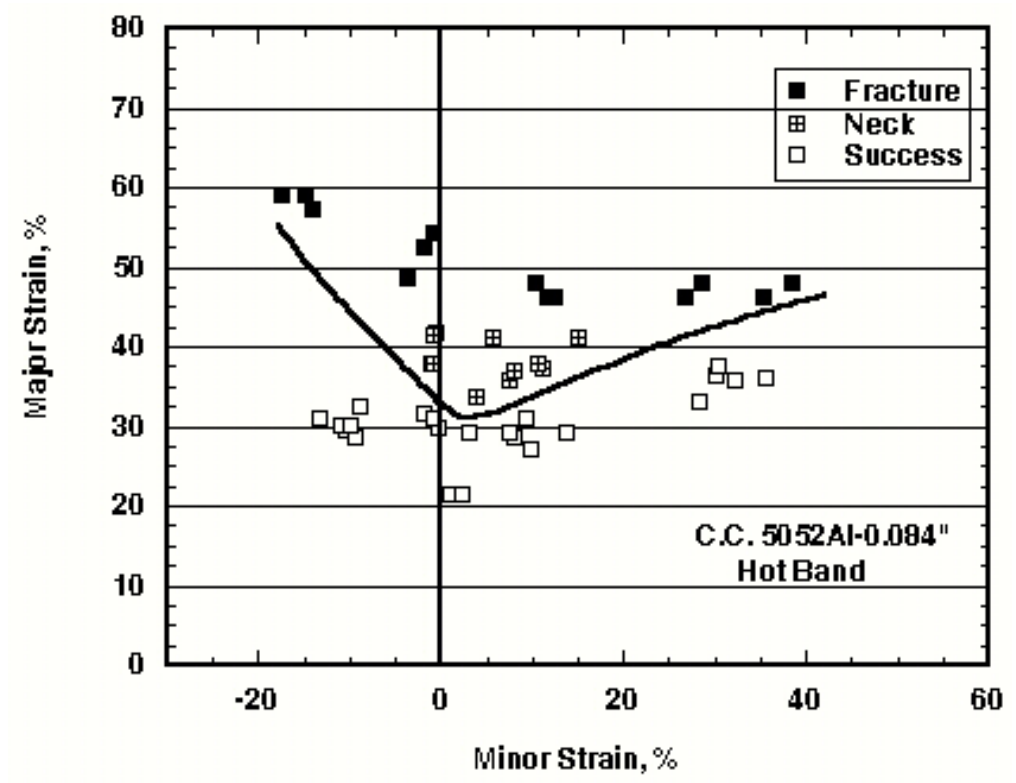

Fig 4: Representative Formability Limit Diagram

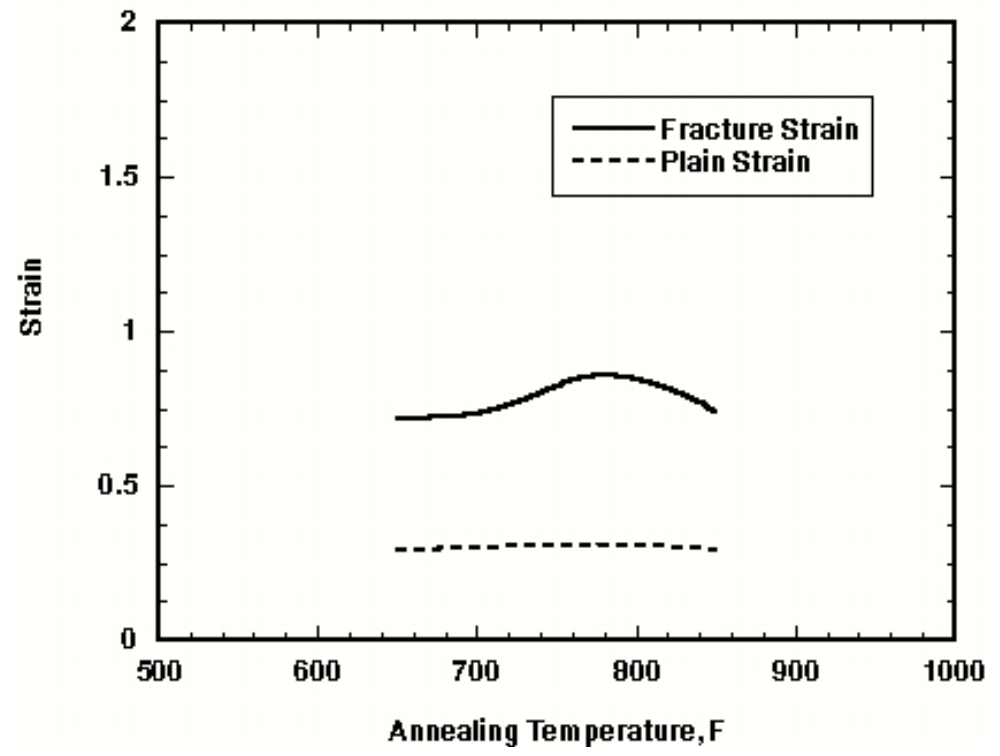

Fig 5: The effect of annealing temperature on the Forming limit strain for plane strain condition as well as biaxial fracture strain

\subsection{4: Discussions}

It has been found that higher degrees of cold rolling increase the amount of retained deformation texture in this material even after the normal recrystallization step. Examination of the intensities of Cube texture (200) shows that decreases in cube intensity occur with increasing cold rolling reduction from 0.125 " to 0.063 " down to 0.030 ". On the other hand, the (111) intensities increase with increasing reduction. Thus under similar annealing conditions, the degree of recrystallization varies in these alloys possibly due to particle pinning. Since recrystallization involves migration 
of grain boundaries, it is believed that inadequate migration of grain boundaries can also leave damage to particle-matrix interfaces produced during rolling. Such damaged interfaces would then lead to void initiation during forming of the sheet and lower the forming limit. We find this the case for sheets rolled to 0.030 ".

The pole intensities in the peak regions show noticeable changes for (111), and (200) pole figures. With increase in reduction during cold rolling followed by annealing, shows that the laboratory process produces more random distribution of crystallite orientations and minimizes the intensity of cube component. This is beneficial for stretch forming application.

The forming limit diagrams for the different in-line annealed samples and the hot band material were studied. Annealing improves formability over the hot band material, but too high a temperature of annealing does not help. The effect is seen more clearly for fracture strain results under biaxial tension, and may be related to coarsening of particles at very high surface temperature. Because of the small difference in the forming limit for the lower annealing temperatures, it is believed that variations in the type of recrystallization may not play a big role on formability as long as recovery and recrystallization effects have removed the cold work sufficiently well.

\section{3 - Oak Ridge National Laboratory}

\subsection{1: In-line Annealing}

This part of the work evaluated rapid heating technology using infrared as a possible alternative to induction heating for in-line annealing of hot band. The experiments described in this subsection describe the ability of the infrared heating sources at ORNL to perform the recrystallization anneals using thermal cycles typical of those experienced by the hot band during in-situ induction heating. Two infrared processing facilities at the Oak Ridge National Laboratory (ORNL) were used to produce a variety of transient heating profiles in aluminum test samples. The time/temperature histories produced in these samples were able to simulate the characteristics of the required thermal profiles for in-line annealing.

Infrared process heating techniques were chosen for the simulation because of the relative simplicity of achieving experimental precision over the wide range of heating rates required to match the in-line annealing requirements. For example, the industrial requirements for providing in-line anneal processing of the sheet, as it exits, the rolling mill at $120 \mathrm{~cm} / \mathrm{s}$ requires heating rates as high as $300^{\circ} \mathrm{C} / \mathrm{s}$. In order to match these very rapid heating rates, a plasma arc lamp system at ORNL was used and found to be very effective in preparing various types of metallurgical specimens.

Experimental Facilities: In order to prepare flash anneal samples at the required rapid heating rates, a $300-\mathrm{kW}$ plasma arc lamp was utilized to produce tensile, earring, and metallography specimens. The capability of this system to anneal several millimeter-thick samples of aluminum is in excess of $1000^{\circ} \mathrm{C} / \mathrm{s}$. Shown schematically in Figure 1 are the basic attributes of the arc lamp.

Arc lamp sources are configured as a simple quartz tube, $4 \mathrm{~cm}$ ID, into which a mixture of dematerialized water and argon are injected (see Figure 1.1). The mixture is injected tangentially into the quartz tube's interior at one end of the tube. The resultant helical flow down the length of the tube produces a thin film of water against the tube wall, which effectively cools it. The argon gas flows in a similar fashion down the core of the tube and provides the medium into which a high-pressure plasma arc can be formed for passing up to 1200 A. These sources are able to 
operate continuously for up to $1000 \mathrm{~h}$. Power output is continuously variable from near $1 \mathrm{~kW}$ to full power and requires only $0.020 \mathrm{~s}$ to ramp up or extinguish.

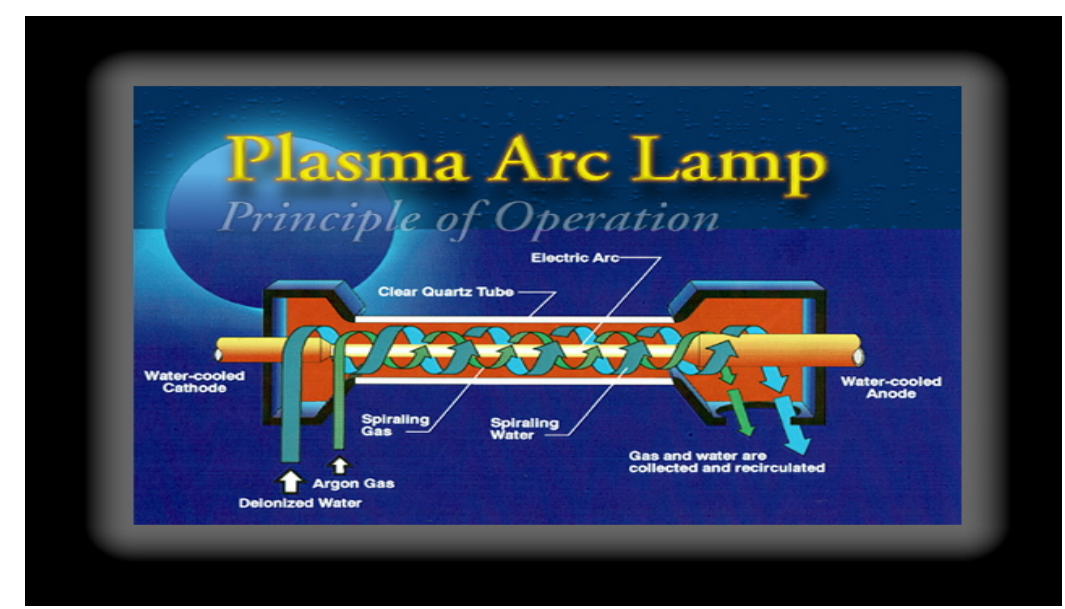

Fig1.1: Schematic of an operational plasma arc lamp

For high power density process heating applications, a suitably designed water-cooled reflector is located around the quartz plasma arc tube as shown in Figure 1.2. A typical system operating at $300 \mathrm{~kW}$ in this configuration would be able to focus a beam over a 2- by $10-\mathrm{cm}$ area at power densities of $3500 \mathrm{~W} / \mathrm{cm}^{2}$.
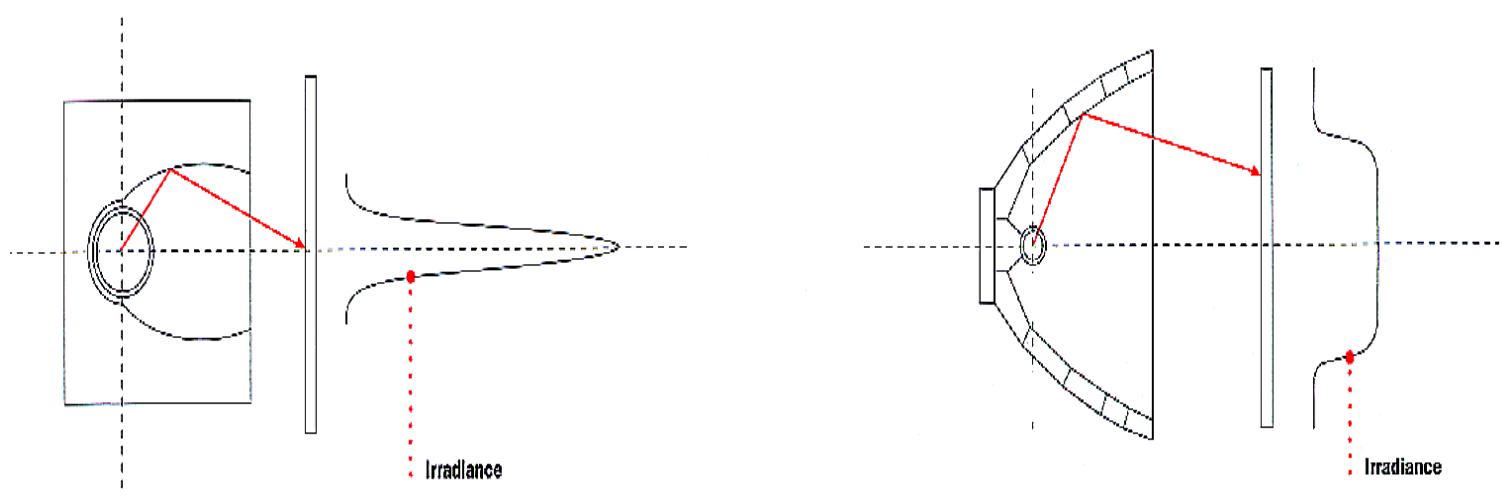

Fig 1.2: Arc lamp reflector configurations.

Other reflectors are available at our Plasma Arc Lamp Facility that provides focused rectangular beam profiles measuring: $3 \mathrm{~cm}$ by $20 \mathrm{~cm}$ and $3 \mathrm{~cm}$ by $35 \mathrm{~cm}$, which produce power densities of $1200 \mathrm{~W} / \mathrm{cm}^{2}$ and $600 \mathrm{~W} / \mathrm{cm}^{2}$, respectively. A uniform irradiance reflector shown in Fig 2 (right), will provide a uniform focus over a $20 \mathrm{~cm}$ by $20 \mathrm{~cm}$ area at $200 \mathrm{~W} / \mathrm{cm}^{2}$.

Fig 3 shows a plan view of the Plasma Arc Lamp Facility at ORNL. Also shown is a close-up of the lamp mounted on a six-axis Cincinnati-Milacron model T3-776 robot. A Universal Robot 
Controller (URC) developed and built by Robot Workspace Technologies, provides precise positioning and scanning capability for the arc lamp head. Using the robot in conjunction with the plasma arc lamp greatly increases the facility's flexibility for performing a variety of experiments. There are also a variety of processing boxes available for the heating of specimens in different atmospheres when using the plasma arc lamp.

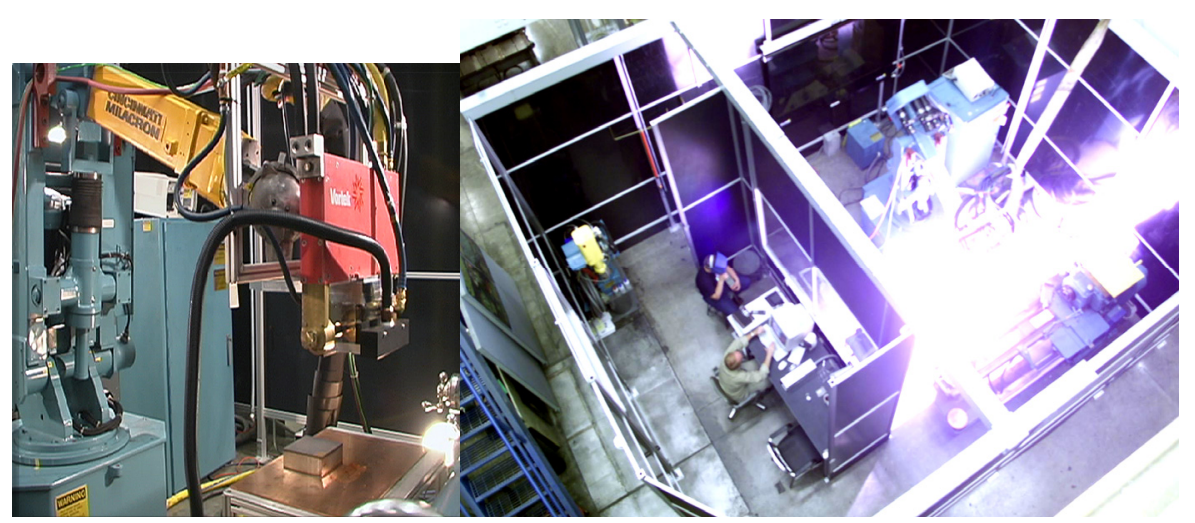

Fig 1.3: Plasma Arc Lamp Facility

On-line video monitoring is available for video recording of experiments from different locations inside the enclosure. PC-based data acquisition is used in the facility and allows for automated temperature, heat flux, and lamp head position/kinematics to be monitored during processing.

The first task that was devised for examination by infrared processing was to simulate millheating profiles that would occur in the continuous-cast hot band as it exits in the rolling mill at $260^{\circ} \mathrm{C}$. The initial series of 1 -s flash anneals performed with the $20-\mathrm{cm}$ plasma arc lamp, microscopic examination of the annealed samples at $372^{\circ} \mathrm{C}\left(700^{\circ} \mathrm{F}\right), 472^{\circ} \mathrm{C}\left(800^{\circ} \mathrm{F}\right)$, and $482^{\circ} \mathrm{C}$ $\left(900^{\circ} \mathrm{F}\right)$ revealed little if any recrystallization of the initial rolled structure, even at the $482^{\circ} \mathrm{C}$ temperature.

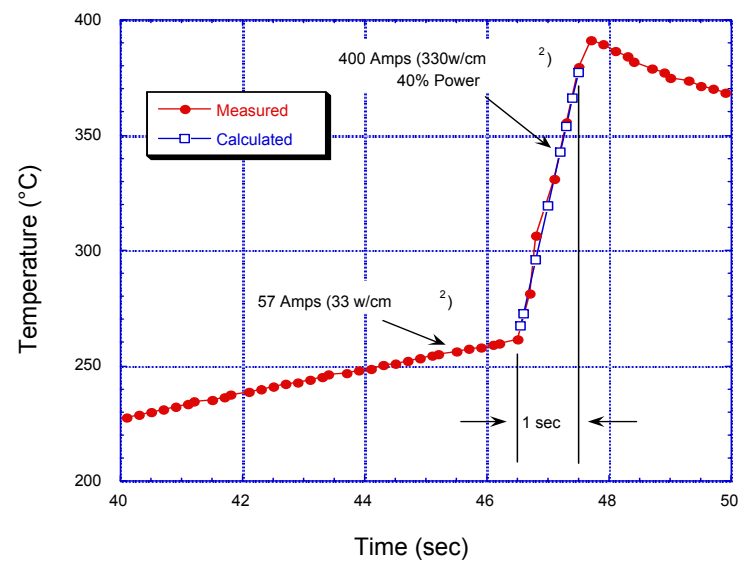

Fig 1.4: Typical temperature response for a 14-cm-long $\times 2$-cm-wide $\times 2$-mm-thick flashannealed tensile specimen processed by the $20-\mathrm{cm}$ plasma arc lamp. 
Another series of tests with the 10 -cm lamp, the flash anneal series at $372^{\circ} \mathrm{C}\left(700^{\circ} \mathrm{F}\right), 472^{\circ} \mathrm{C}$ $\left(800^{\circ} \mathrm{F}\right)$, and $482^{\circ} \mathrm{C}\left(900^{\circ} \mathrm{F}\right)$ was repeated with the new sized specimens. In addition, a new series was added $\left[510^{\circ} \mathrm{C}\left(950^{\circ} \mathrm{F}\right), 537^{\circ} \mathrm{C}\left(1000^{\circ} \mathrm{F}\right)\right.$, and $\left.565^{\circ} \mathrm{C}\left(1050^{\circ} \mathrm{F}\right)\right]$. The flash-anneal cycle temperature response plots for this $10-\mathrm{cm}$ arc lamp series is shown in Figure 1.7. The micrographs that were made for the $510^{\circ} \mathrm{C}\left(950^{\circ} \mathrm{F}\right), 537^{\circ} \mathrm{C}\left(1000^{\circ} \mathrm{F}\right)$, and $565^{\circ} \mathrm{C}\left(1050^{\circ} \mathrm{F}\right)$ temperature series are shown in Figure 1.8 and clearly indicate that complete recrystallization has occurred at all three higher temperatures.

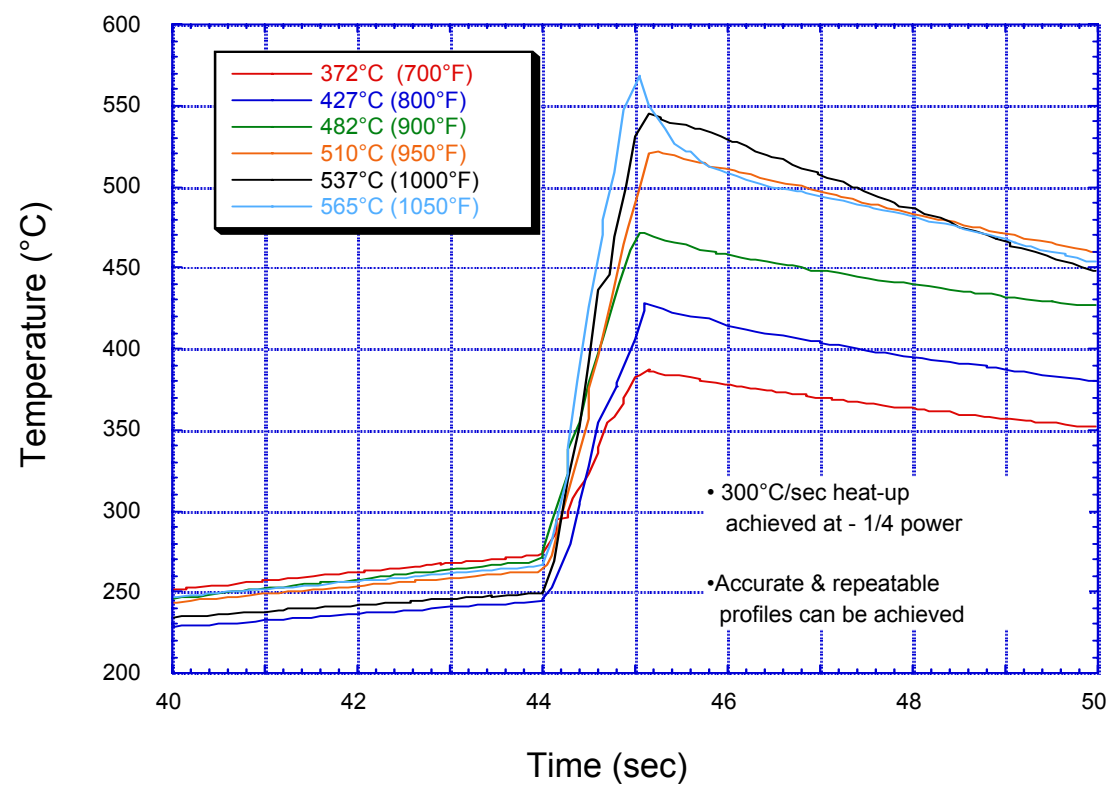

Fig 1.5: Typical temperature responses for a 10-cm-long $\times 1$-cm-wide $\times 2$-mm-thick flashannealed tensile specimen processed by the $10-\mathrm{cm}$ plasma arc lamp. 

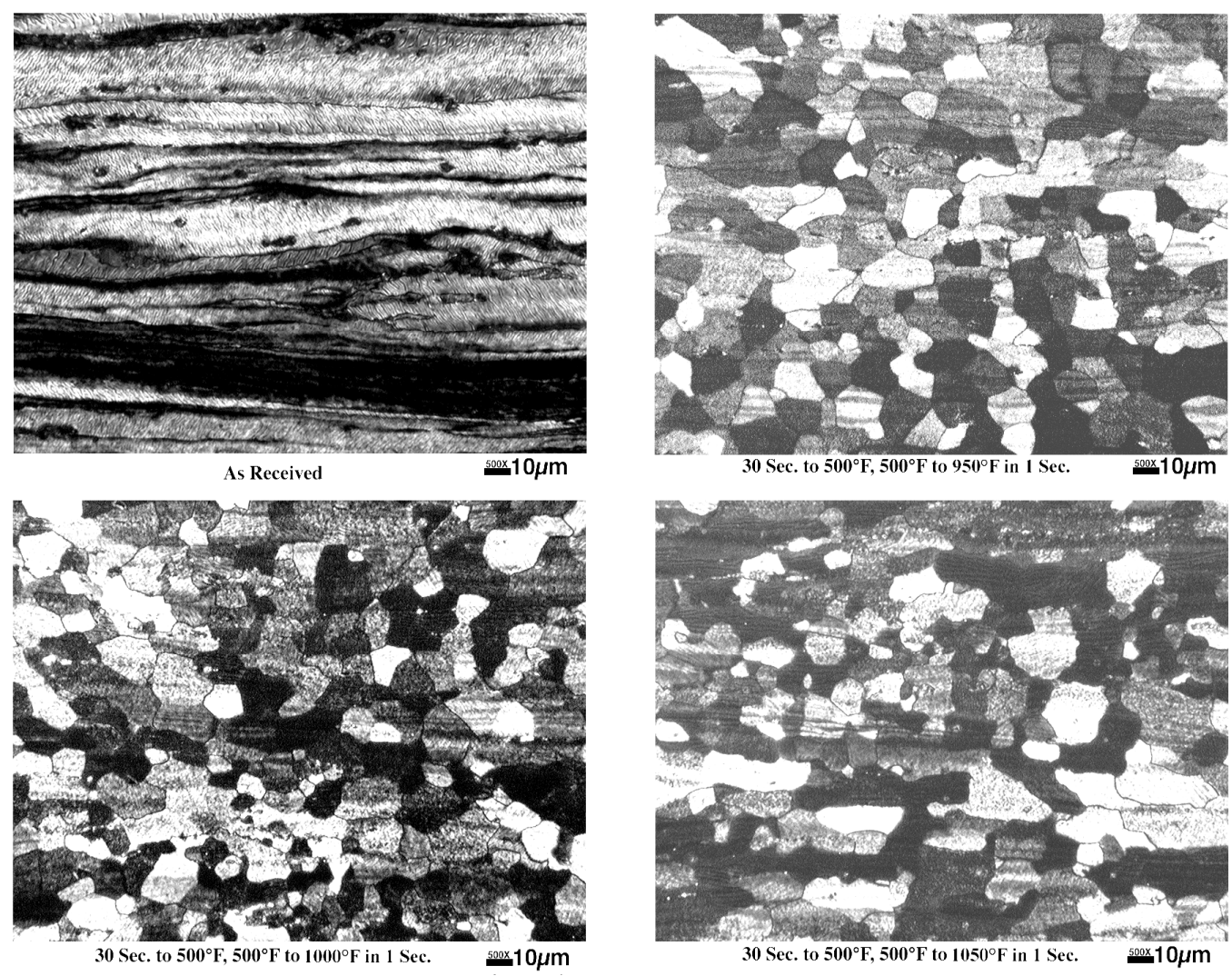

Fig 1.6: Microstructure - flash annealed at $510^{\circ} \mathrm{C}\left(950^{\circ} \mathrm{F}\right), 537^{\circ} \mathrm{C}\left(1000^{\circ} \mathrm{F}\right)$, and $565^{\circ} \mathrm{C}\left(1050^{\circ} \mathrm{F}\right)$. As-received rolled structure has been completely recrystallized

Gleeble Studies: The purpose of this effort was to use an alternate, independent rapid heating technology to test the validity of the results obtained using infrared heating. Gleeble thermomechanical device is capable of heating small coupons at a rapid rate using controlled, resistive heating with the sample thermal history carefully recorded using a thermo-couple attached to the specimen. The Gleeble thermo-mechanical simulator uses samples in the form of strips 6" long and 1" wide. The sample is gripped in water-cooled copper jaws at its ends with a gauge-length of roughly 2" between the jaws. The copper jaws and the sample form the secondary of a transformer and resistance heated by passing current through the sample. The power to the sample is controlled by a thermocouple which is spot welded to the midpoint of the gauge length. The thermocouple provides feedback control by sensing the difference between the sample temperature and a program temperature. Initial experiments using the Gleeeble for heating a 0.080" thick CC hot band were quite successful. Samples could be heated from 500F to 900F in 0.75 seconds without overheating the samples. Tensile testing of the Gleeble samples after thermal cycling showed a roughly 50\% reduction in yield strength compared to the as-received, indicating significant microstructural change. However, the elongation to failure was lower than that of the as-received hot band, because of the presence of the Type-K thermocouple junction that was spot welded to the sample and the alloying between the thermocouple junction and aluminum sheet during the thermal cycle.

Further experiments were conducted using the Gleeble with the thermocouples welded away from the center-line of the samples such that the welds could be removed after Gleeble testing. Tensile testing of the Gleeble samples showed both significant softening as in the previous trials with a roughly $50 \%$ reduction in yield strength and a much improved tensile elongation compared to the 
previous samples that contained the thermocouple welds. The tensile elongation in the rolling direction increased from about $12 \%$ for the as-received sample to about $14 \%$ in the heat treated sample. However, there was a sample-to-sample variability of about $2 \%$ for the Gleeble samples. The tensile elongation in the transverse direction increased significantly from about $10 \%$ for the as-received samples to about $14 \%$ for the Gleeble samples.

\subsection{2: Optimization Modeling}

The objectives of this task include (a) analytical modeling to predict recrystallization kinetics of CC 5XXX alloys under continuous heating and cooling conditions, as in in-line annealing (b) continuum modeling of hot deformation to quantify the through-thickness deformation gradient in hot band and its relevance to recrystallization kinetics and (b) microstructural evolution modeling to predict the evolution of microstructure and texture during recrystallization of CC5xxx alloys. Experimental results described in the previous sections on advanced characterization and plasma heating was used as inputs to the model, as well as to validate some of the model predictions. The experimental data obtained during in-plant trials of in-line annealing were also used to validate some of the modeling results.

The modeling approach included the following subtasks:

- performing isothermal recrystallization experiments and calculate the recrystallization fraction as a function of time

- use of the Johnson-Mehl-Avrami-Kolmogorov (JMAK) equation to obtain an analytical expression for the recrystallization kinetics and extract the activation energy for recrystallization and other related coefficients to describe the recrystallization kinetics at various temperatures,

- modification of the JMAK approach to predict the recrystallization kinetics under continuous heating and cooling conditions and

- validation of the model predictions using experimental data

Isothermal Recrystallization Kinetics: Isothermal recrystallization experiments were carried out in a Gleeble thermo-mechanical simulator. The Gleeble samples in the form of rectangular strips of 5 " $\mathrm{x} 0.5$ " were rapidly heated to the peak temperature in about 1 second, in a Gleeble thermomechanical simulator, held isothermally for the required amount of time and cooled rapidly to room temperature. The isothermal recrystallization kinetics was studied at $690 \mathrm{~F}, 720 \mathrm{~F}$ and $750 \mathrm{~F}$. The heating rate was high enough to prevent significant recrystallization from occurring on heating. Tensile samples were machined normal to the rolling direction. The samples were tested in tension in order to determine the yield strength after various isothermal holds at the peak temperature. The recrystallized fraction was calculated as $\left(\mathrm{y}_{0}-\mathrm{y}_{\mathrm{t}}\right) /\left(\mathrm{y}_{0}-\mathrm{y}_{\infty}\right)$, where $\mathrm{y}_{0}$ is the yield strength of the hot band, $\mathrm{y}_{\mathrm{t}}$ is the yield strength after an isothermal hold for $t$ seconds, and $\mathrm{y}_{\infty}$ is the yield strength after complete recrystallization has occurred.

Analytical Modeling of Recrystallization Data: The experimental data points were fitted to a Johnson-Mehl-Avrami-Kolmogorov (JMAK) equation of the form

$$
f_{\text {rex }}=1-\exp \left(-k t^{n}\right)
$$


where $k$ is a temperature-dependent constant and $n$ is a roughly temperature-independent constant commonly known as the JMAK exponent which depends both on the nucleation and growth aspects of recrystallization. The experimental data and the JMAK fit to the data are shown in figure 2.1 (left). From the JMAK fit to the data points, the constants $k$ and $n$ were obtained for the three experimental temperatures. From the fit equations, the time for $50 \%$ recrystallization, $t_{50}$ were obtained. The apparent activation energy for recrystallization was calculated from the slope of the Arrhenius plot of $\log \left(t_{50}\right)$ versus $1 / T$ where $T$ is the recrystallization temperature in $\mathrm{K}$. This is shown in figure 2.1(right).
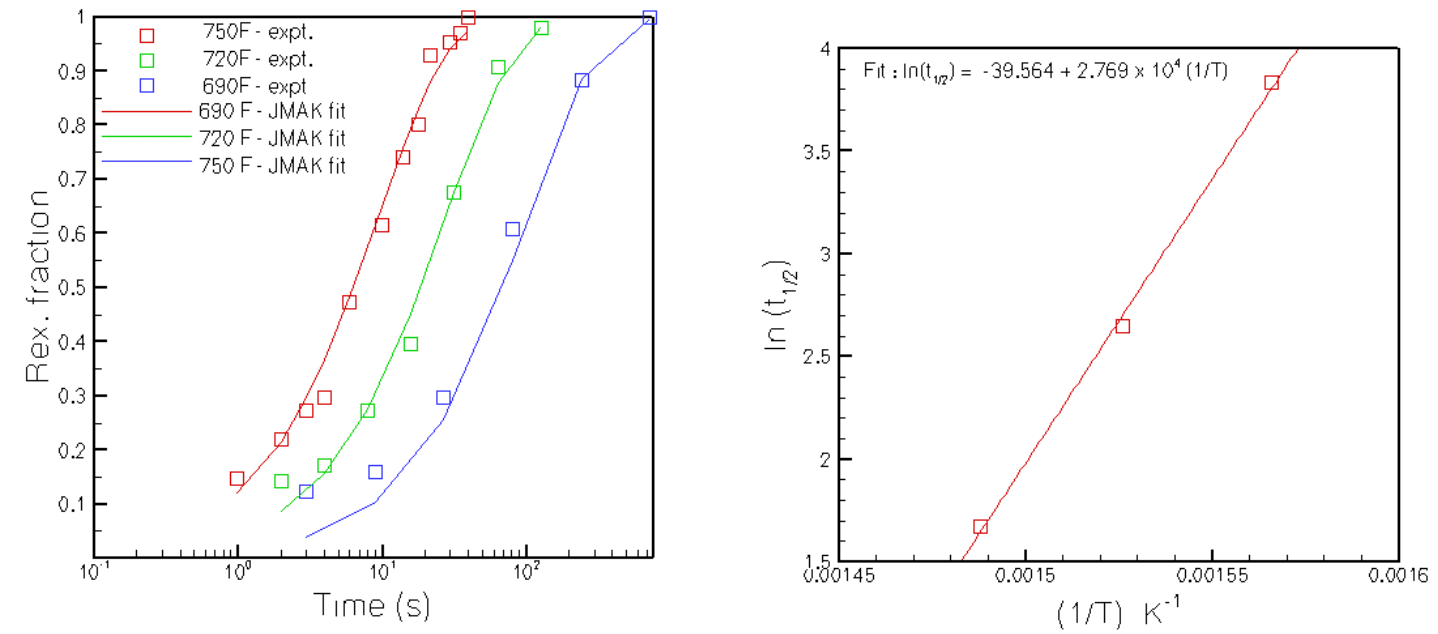

Fig 1.7: Isothermal recrystallization kinetics for AA5754 and JMAK fit (left) and Arrhenius plot showing the activation energy for recrystallization

From figure 1.7 (right), the apparent activation energy of recrystallization has been estimated to be $232 \mathrm{~kJ} / \mathrm{mol}$.

Recrystallization kinetics under continuous heating and cooling: A continuous heating and cooling cycle such as the one experienced during inline annealing and coiling of the hot band can be broken down into a number of isothermal holds and various temperatures. The total recrystallization during the entire thermal cycle can be obtained by summing the recrystallization fraction during each isothermal step. However, this approach assumes that the activation energy for recrystallization is constant in the temperature range of the thermal cycle. The form of the JMAK equation used in this case is given by

$$
f_{\text {rex }}=1-\exp \left[-\sum_{t=0}^{t=t} k(T) \Delta t^{n}\right]
$$

where $\mathrm{k}(\mathrm{T})$ is given by

$$
k(t)=k_{0} \exp \left(-\frac{Q}{R T}\right)
$$

The constant $k_{0}$ is obtained from the known values of $k$ and the activation energy $Q$ obtained from the JMAK fit to the isothermal experimental data. 
Application of the model to recrystallization data: The above approach was used to predict the extent of recrystallization during thermal cycling such as the ones used in flash annealing experiments and the thermal cycling experienced by the hot band during in-line annealing followed by coiling and the cooling of the coil..

Application to flash annealing data: The analytical model has been used to predict the recrystallized volume fraction after a rapid heating to various peak temperatures in 1.0 second, in order to compare with the earlier IR heating experiments. A linear heating to the peak temperatures was assumed.
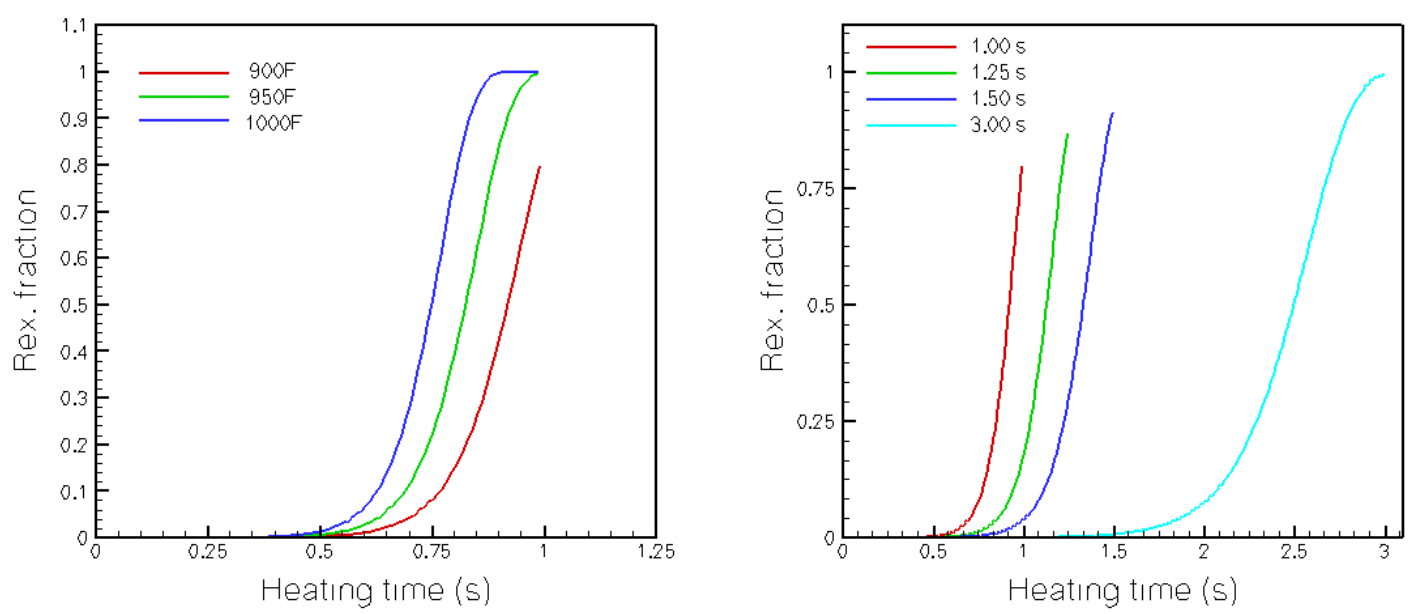

Fig 1.8: Recrystallization kinetics during continuous heating showing the recrystallization fraction on heating to various peak temperatures in $1.0 \mathrm{~s}$ (left) and the heating time required to obtain complete recrystallization for a peak temperature of $900 \mathrm{~F}$ (right)

Figure 1.8 shows the results from the model. According to the model, an outlet hot band temperature in excess of $950 \mathrm{~F}$ is required in order to fully recrystallize the material on heating from $500 \mathrm{~F}$ to the peak temperature in $1.0 \mathrm{~s}$. This is in excellent agreement with the experimental data using IR heating. Figure 2.2 also shows that if the peak temperature is limited to $900 \mathrm{~F}$, a heating time of about $3.0 \mathrm{~s}$ is required to obtain complete recrystallization in the hot band. This may be applicable to higher gage hot bands with lower line speeds. Essentially, the model can handle any thermal cycle that includes the heating rate and the cooling rate in the coil.

Application to In-line annealing and coil cooling: The analytical model was applied to study the recrystallization kinetics of $\mathrm{CC}$ hot band under continuous heating and cooling conditions. The thermal history of the hot band is determined by the heating associated with in-line annealing followed by cooling in the coil. The coil cooling data for conventionally produced (without inline annealing) coils were available for a coiling temperature of about 500F. The data was extrapolated to higher temperatures in order to study the effect of in-line annealing. For the smaller coils that were produced during in-line annealing experiments at Carson, the cooling date was available for higher initial temperatures, since the hot band was subjected to in-line annealing. The heating rate to the peak in-line annealing temperature was calculated on the basis of the line speed and the dimensions of the in-line annealing furnace. 
The analytical model prediction matches reasonably closely with that of actual trials. Therefore, there was an excellent agreement between the model predictions and the in-line annealing data.

One of the consequences of rolling is a deformation gradient in the through-thickness direction of the sheet. The surface experiences shear loads because of the friction between the rolls and the hot band, while mid-thickness region mainly experiences plane strain compression. In order to quantify the differences between the deformation characteristics of the surface and center, the deformation of the hot band during hot deformation was simulated using a finite element model.

Continuum modeling of rolling of hot band: In this task the hot deformation of AA5xxx alloy was modeled using the ABAQUS Explicit finite element code. One of the key inputs to the models is the constitutive behavior of the as cast material during deformation. The required data was generated by performing laboratory scale, hot compression tests on hot band as described below.

Tests indicate that the yield strength at the temperature is sensitive to the strain rate, the behavior known as viscoplastic effect. Although not shown here, the viscoplastic behavior was exhibited at all temperature levels tested.

Fig 1.9a, $\mathrm{b}$ and $\mathrm{c}$ below shows the variation of equivalent plastic strain in the through-thickness direction during rolling of the alloy

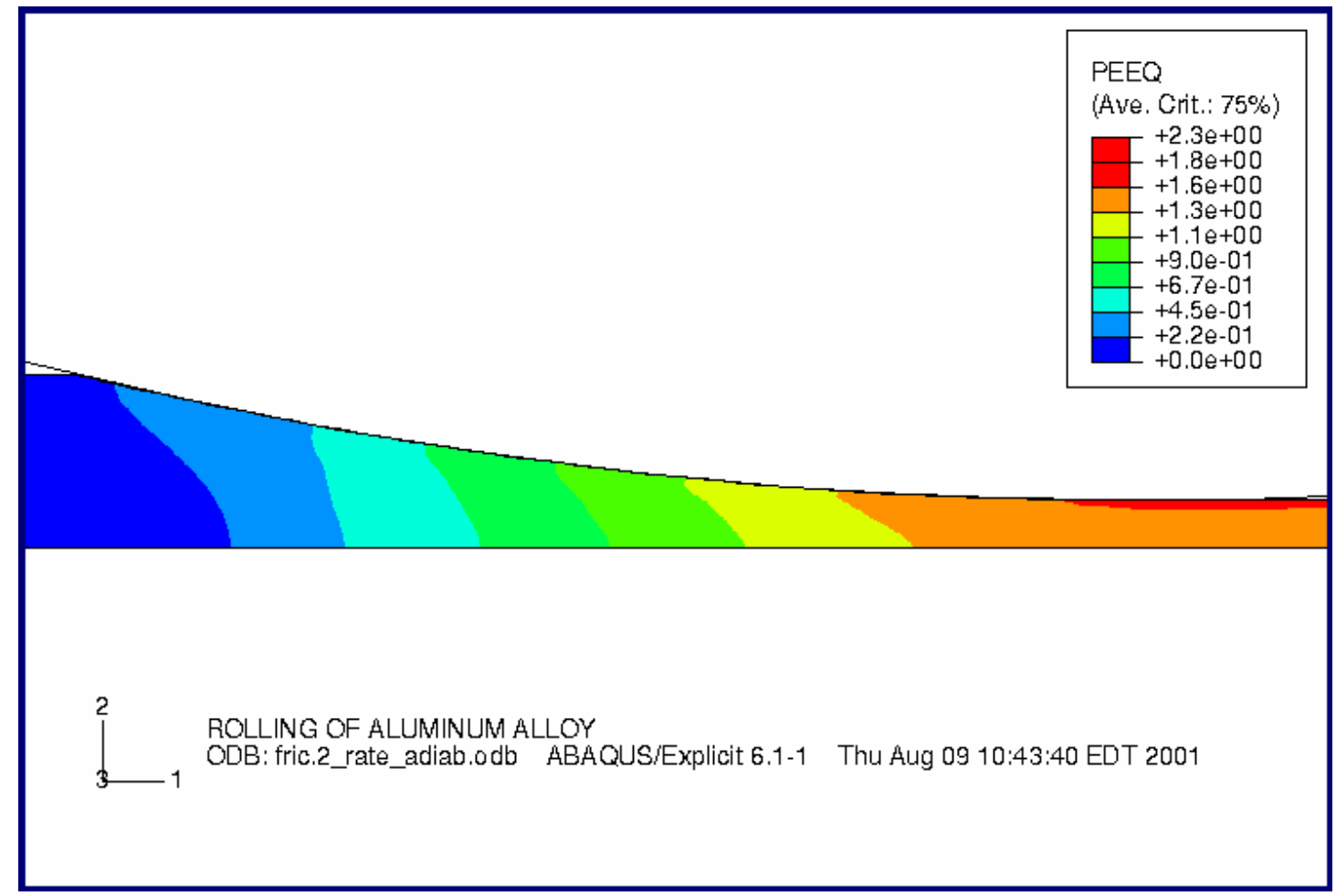

Fig 1.9a: Variation of equivalent plastic strain in the through-thickness direction during hotrolling of 5xx Friction coefficient between the roll and sheet is 0.2 


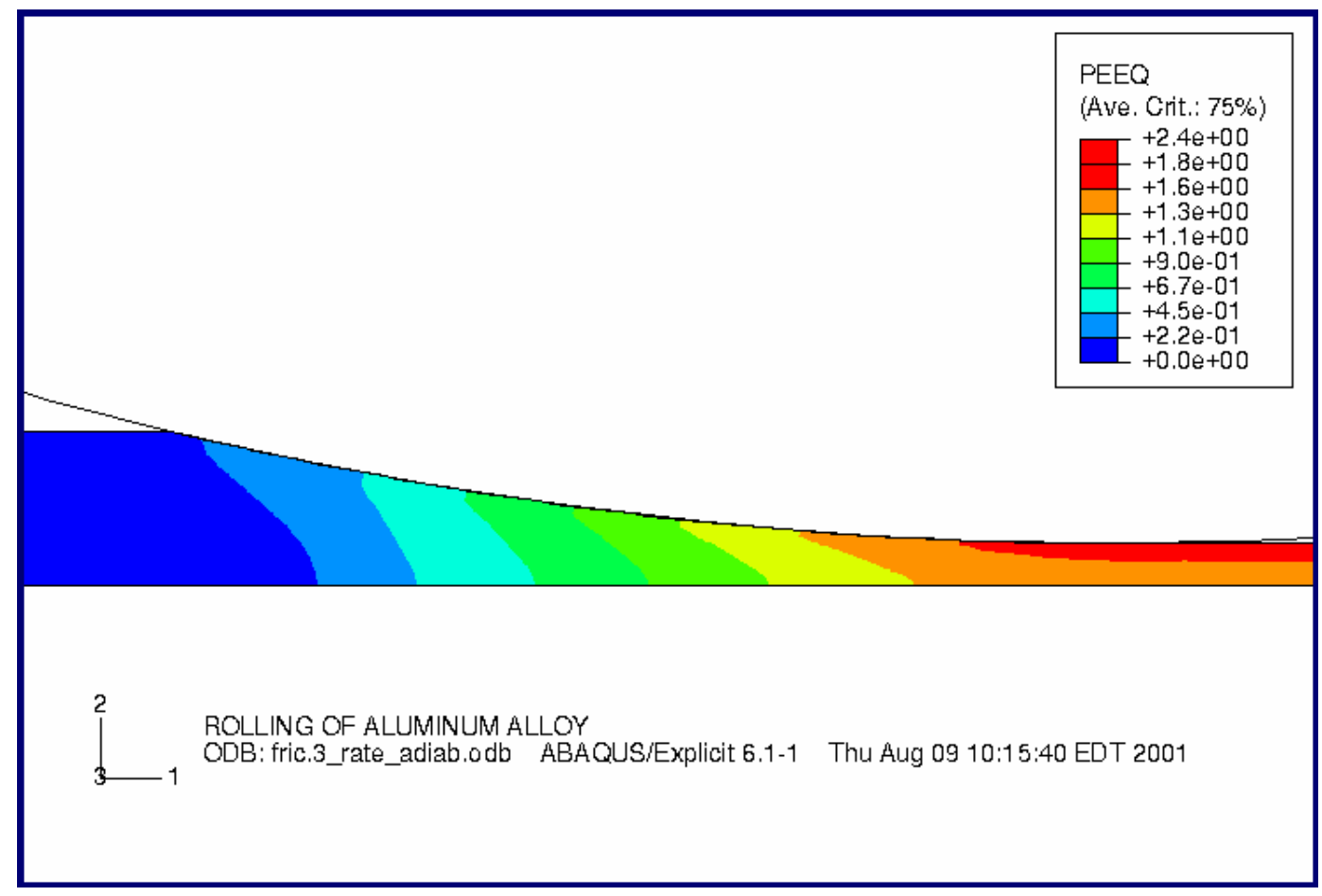

Fig 1.9b: Variation of equivalent plastic strain in the through-thickness direction during hotrolling of AA5754. Friction coefficient between the roll and sheet is 0.3

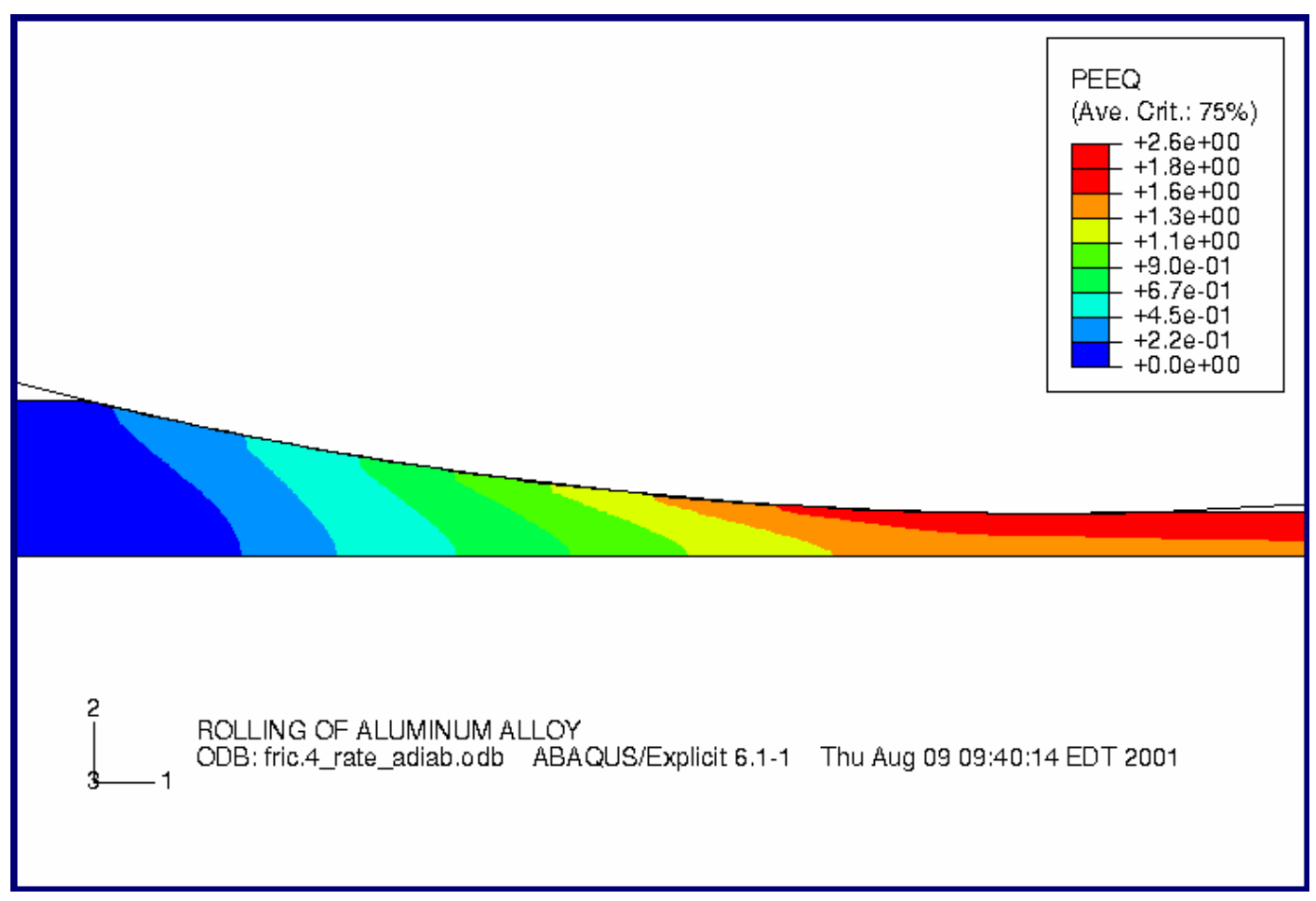

Fig 1.9c Variation of equivalent plastic strain in the through-thickness direction during hot-rolling Friction coefficient between the roll and sheet is 0.4 . 
There is a qualitative agreement between the model predictions and experimental data with regard to the variation of stored energy of deformation in the through-thickness direction. A higher plastic strain (and therefore, a higher stored energy of deformation) in the surface compared to the center will result in faster recrystallization kinetics at the surface, and also will result in a finer recrystallized grain size..

Modeling of microstructural evolution during recrystallization: The objective of the microstructural evolution modeling is to understand the evolution of microstructure and texture during recrystallization either under isothermal conditions or under the continuous heating and cooling conditions experienced by the hot band during in-line annealing and coil cooling. The modeling approach is based on a Monte Carlo technique that was developed at ORNL through funding from DOE's Basic Energy Sciences program. The technique and its application to the evolution deformation substructures in well documented in the literature and will not be repeated here.

One of the important inputs to the Monte Carlo code is the deformation substructure of the hot band. In the current project, the deformation substructure of the hot band was obtained from EBSP data. The input data consists of an ordered set of scan sites in the form of a triangular grid, and the crystallographic orientation of each site in the form of the three Euler angles. The Monte Carlo code developed as part of the BES program was modified to handle the EBSP data. In aluminum alloys, recrystallization can be considered as an abnormal subgrain growth process, where selective subgrain growth due to either a size advantage or a growth advantage or both cause strain free nuclei form. The nuclei then grow in an abnormal fashion to consume the deformation substructure. The recrystallization process stops when all the growing nuclei overlap, and this is followed by a grain growth process. The Monte Carlo approach can conveniently handle both the recrystallization and grain growth stages.

The EBSP facilities that existed at ORNL at the beginning of the CRADA were not powerful enough to produce large orientation data sets that are required for a statistically significant representation of the hot band microstructure, although the small data sets were useful for characterizing the deformation substructures and recrystallized grain structures in laboratory annealing experiments as described in task 4.1. With the updating of the EBSP facilities in the second year of the CRADA at ORNL it was possible to collect significantly larger data sets which a high degree of spatial resolution. The simulation results shown in this report correspond to those where the model input consisted of these large orientation data sets. The typical size of the scan was about $800 \times 800$ sites with a step size of $0.5 \mu \mathrm{m}$. The input data consisting of the coordinates of the scan sites and the Euler angles corresponding to each location mapped on to a twodimensional triangular lattice.

One of the unique features of the simulations was the ability to realistically incorporate in the simulations the relevant subgrain boundary properties that are critical to their migration boundary mobility and boundary energy. In aluminum alloys the deformation substructure consists of a wide range of boundary types. In general the boundaries can be classified as high angle grain boundaries (HAGBs) and low angle grain boundaries (LAGBs). Some of the HAGBs are characterized by some special misorientations that result in the formation of special boundaries that have low boundary energy and high boundary mobility. In aluminum alloys, the most relevant special boundaries are those that are misoriented by a $40^{\circ}<111>$ rotation. These are also known as $\Sigma 7$ boundaries. As the misorientation deviates from the ideal $40^{\circ}<111>$ rotation, the properties change rapidly. For example, the boundary energy increases and the boundary mobility decreases with increasing misorientation. When deviation from the ideal misorientation exceeds a critical value the special boundaries can be treated as general boundaries. For general boundaries the boundary energy is related to the misorientation through the Read-Schockley 
model, and the relative boundary mobility as a function of misorientation varies according to an experimentally observed sigmoidal relationship

Figure 1.10 shows the temporal evolution of the deformation substructure of AA5754 hot band. The colors indicate the rotation angle of the axis-angle pair that represents grain boundary misorientation from cube. Red indicates orientations close to Cube orientation and blue indicates regions which are rotated by the highest possible angle, namely, $62.4^{\circ}$ for cubic crystal structures. It is clear that the volume fraction of regions close to Cube in the initial deformation structure is very small. Large cube bands that are typically observed in DC materials are not seen. As the structure evolves, there is no preferential growth of the cube orientations, and therefore the final structure does not contain a strong cube texture. These results are in good agreement with experimental findings.

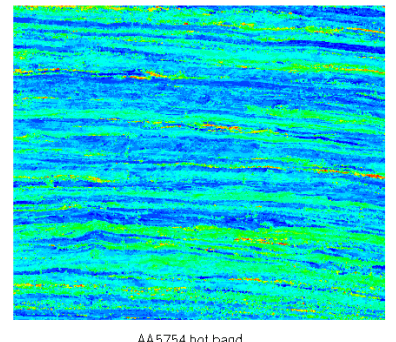

AA5754 hot band

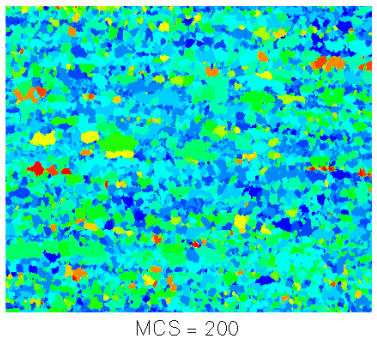

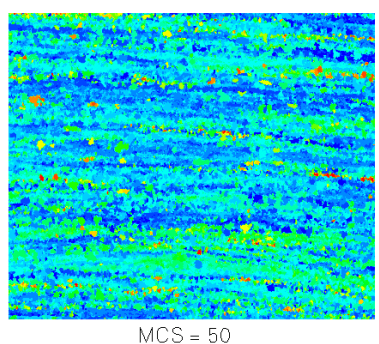

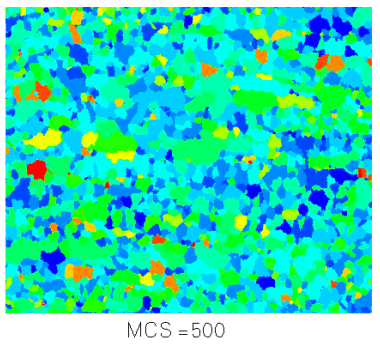

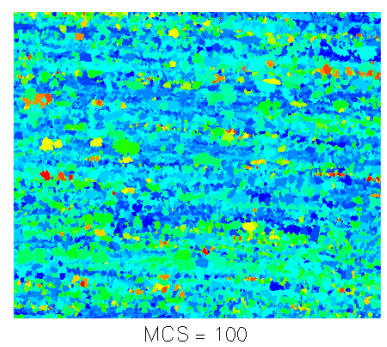

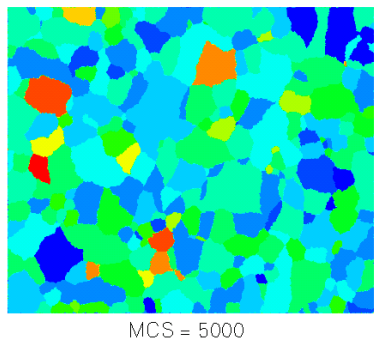

Fig 1.10: Temporal evolution of deformation substructure in AA5754 during recrystallization.

The initial hot band microstructure consists of a large number of small cells approximately 2-3 microns in diameter. Recrystallization involves the abnormal growth of these subgrains to form large grains. Figure 1.11 shows the initial texture and the texture after recrystallization. Recrystallization causes a significant redistribution of the rolling texture components caused by the preferential growth of some components at the expense of the other. Also, the cube component strengthens somewhat, allowing it to be actually seen in the contour plot after recrystallization. 

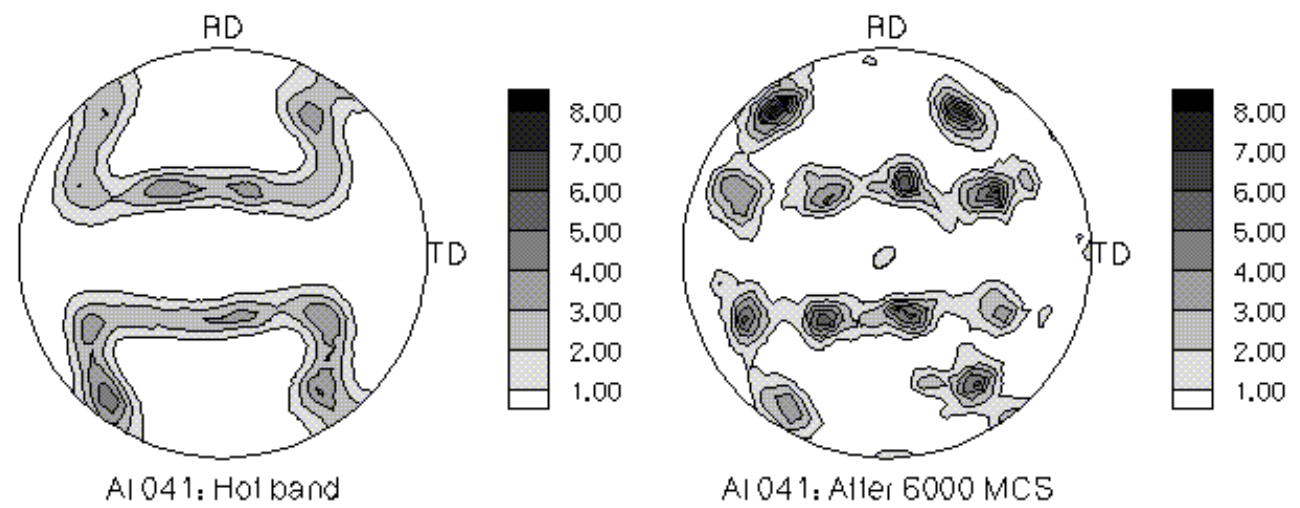

Fig 1.11: $<100>$ contour plots obtained using simulation data showing the deformation texture in the hot band (left) and the redistribution of intensities following recrystallization (right)

However, the change in the texture following recrystallization varied from one location to the other, indicating that it is very sensitive to the initial microstructure texture. In several instances, recrystallization appeared to weaken the deformation texture, and make the texture more random, again in agreement with the experimental measurements shown in section 4. A typical example from simulations where a weakened recrystallization texture develops from a rolling texture is shown in figure 1.12 .
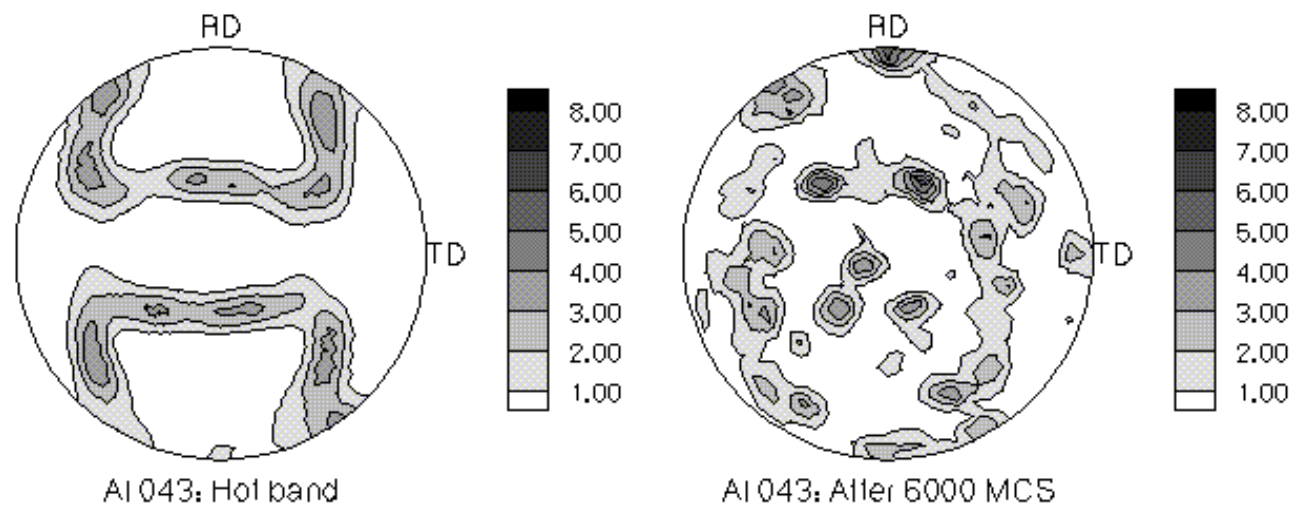

Fig 1.12: $<100>$ contour plots obtained using simulation data showing deformation texture in the hot band (left) and a weakened recrystallization texture after recrystallization (right).

Similar investigations were carried out using several input data sets collected from several locations. The behavior of the Cube texture component during recrystallization is shown in figure 1.13 for several such data sets. In all of these runs, the Cube volume fraction never increased to levels that are normally found in hot bands produced by the conventional DC process. 


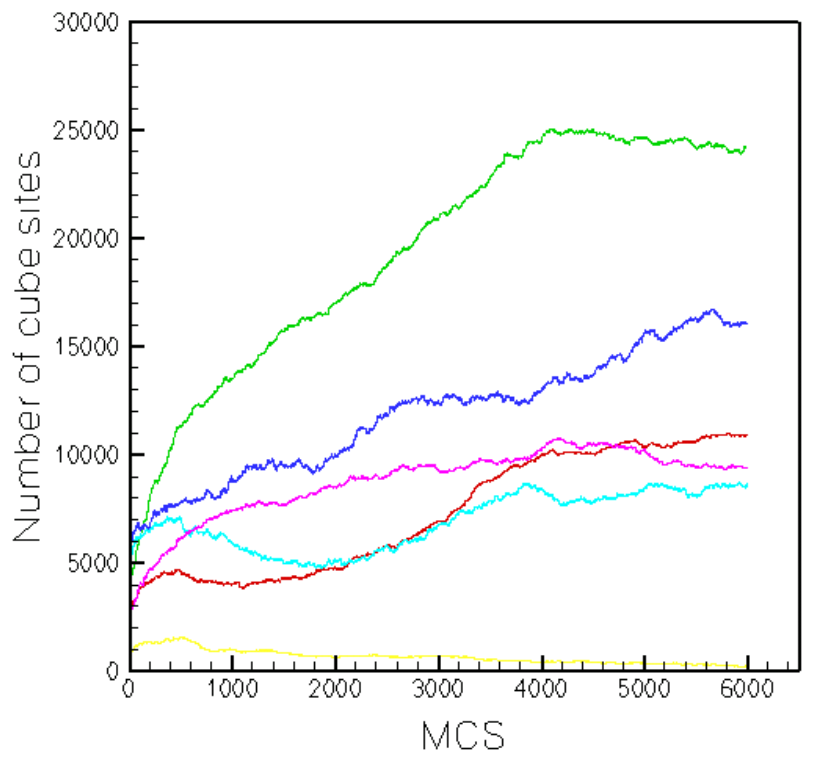

Figure 1.13: Evolution of the Cube orientation during recrystallization of the AA5754 hot band

In the above simulations, the simulation time is given in Monte Carlo time steps (MCS) which is the real time corresponding to one reorientation attempt per site for all the sites in the lattice. It is related to the real time through atomic jump frequency and the recrystallization temperature. In order to express the MCS in terms of the real time it is necessary to know the apparent activation energy for recrystallization. From knowledge of the activation energy, it is possible to relate the Monte Carlo Step (MCS) to real time using the following procedure. We know that the MCS is related to the real time as

$$
M C S=k_{2} T
$$

where $\mathrm{K}_{2}$ is a temperature dependent constant given by eqn. 3 .

$$
K_{2}=K_{2}^{0} \exp (Q / R T)
$$

where $K_{2}^{0}$ is a constant and Q is the activation energy. The isothermal recrystallization data for $690 \mathrm{~F}$ shown in figure indicates that recrystallization is complete after about 32 seconds. A criterion for complete recrystallization is assumed based on the grain size. From experimental samples, it was found that at the time of complete recrystallization the mean grain size was about $30 \mu \mathrm{m}$. From the Monte Carlo simulations, the MCS at which the grain size reaches $30 \mu \mathrm{m}$ is known. Using the two known quantities of time for complete recrystallization and the MCS corresponding to complete recrystallization, the quantity $k_{2}$ was calculated. $K_{2}^{0}$ can then be 
calculated from eqn. 5 . Figure1.15 shows the use of such an approach to relate the real time to MCS for the isothermal recrystallization data shown in section ..

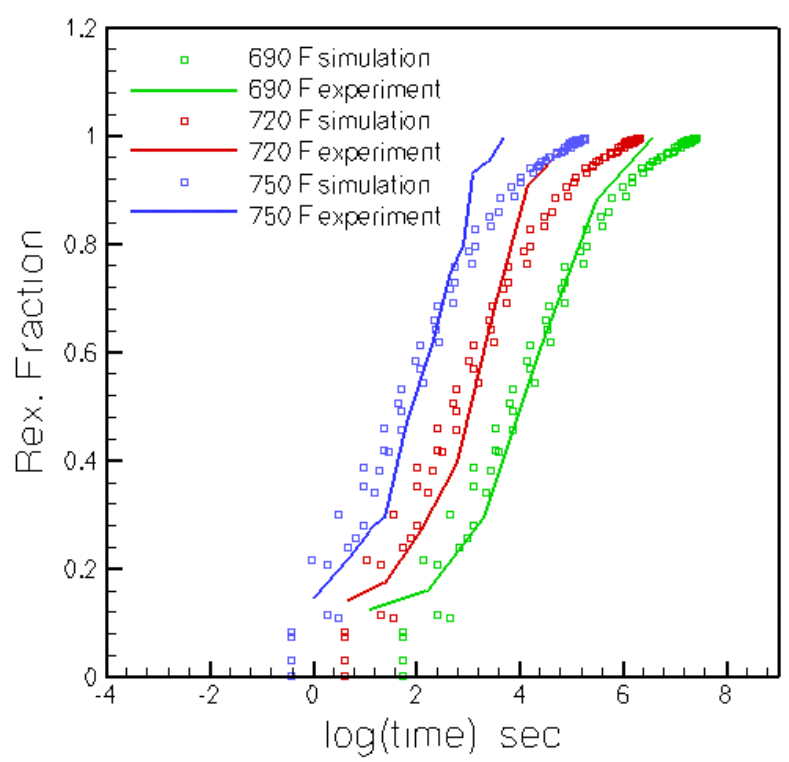

Fig 1.15: Comparison of the isothermal recrystallization kinetics obtained experimentally and the kinetics obtained through Monte Carlo simulations.

Figure 1.15 shows that the above methodology for calculating the relationship between MCS and real time, $t$, provides a reasonably accurate estimate for $\mathrm{K}_{2}$. for all three temperatures.

The above procedure can be easily extended to simulate recrystallization kinetics under nonisothermal conditions (such as in in-line annealing). A continuous thermal cycle can be broken down into a number of isothermal steps at various temperatures. For each isothermal step, an equivalent number of MCS is calculated using the procedure outlined above. Therefore, a given thermocycle can be broken down into an effective number of MCS. The microstructure simulation code can then be used to calculate the extent of recrystallization occurring during a given thermal cycle. The Monte Carlo code has been modified to handle the calculation of MCS for a given thermal cycle. The code has been transferred to the industry (Secat) and a Secat staff was trained to operate the code.

The microstructure evolution modeling and its application to in-line annealing were quite successful. The simulations are able to predict with reasonable accuracy the recrystallization kinetics, the microstructure and texture evolution during an inline annealing thermal cycle. The only adjustable parameter in the microstructure simulation is $K_{2}^{0}$. However, the model assumes that the activation energy for recrystallization is constant in the temperature range of annealing and that the nucleation rate is not a function of temperature. Both of these assumptions are fairly reasonable for the recrystallization of $\mathrm{CC}$ hot band.

\section{Advanced Microstructural Characterization of Hot Bands:}

The advanced microstructural characterization effort had two primary goals; 1 ) to characterize the microstructure and microtexture of the 5754 hot band in the as-rolled and flash annealed conditions and 2) to provide initial and final microtexture data for the recrystallization modeling 
in order to validate the results of the simulations. The characterization effort primarily utilized orientation imaging microscopy (OIM) in a field emission scanning electron microscope with some transmission electron microscopy (TEM) to examine the deformation and precipitation structure at smaller length scales. The OIM is based on the determination of local crystallographic information at the surface of bulk specimens with electron backscattered diffraction (EBSD).

There was initial difficulty in preparing specimens with high quality surfaces (finish and absence of damage) to produce EBSD patterns of sufficient clarity to permit rapid, automated analysis by the OIM system. Specimen quality was hampered both by the coarse oxide and intermetallic stingers and the deformed structure of the as-rolled material. However, a combined technique utilizing a final electropolish typical of the preparation of TEM specimens was developed. This technique successfully produces specimens with the prerequisite high quality surfaces for OIM. More than 40 OIM maps were acquired from a variety of material conditions, positions and orientations relative to the as-rolled material. Even at the $\sim 0.8$ second per pixel acquisition speed of the current OIM system, the OIM maps required from 8 to 24 hours.

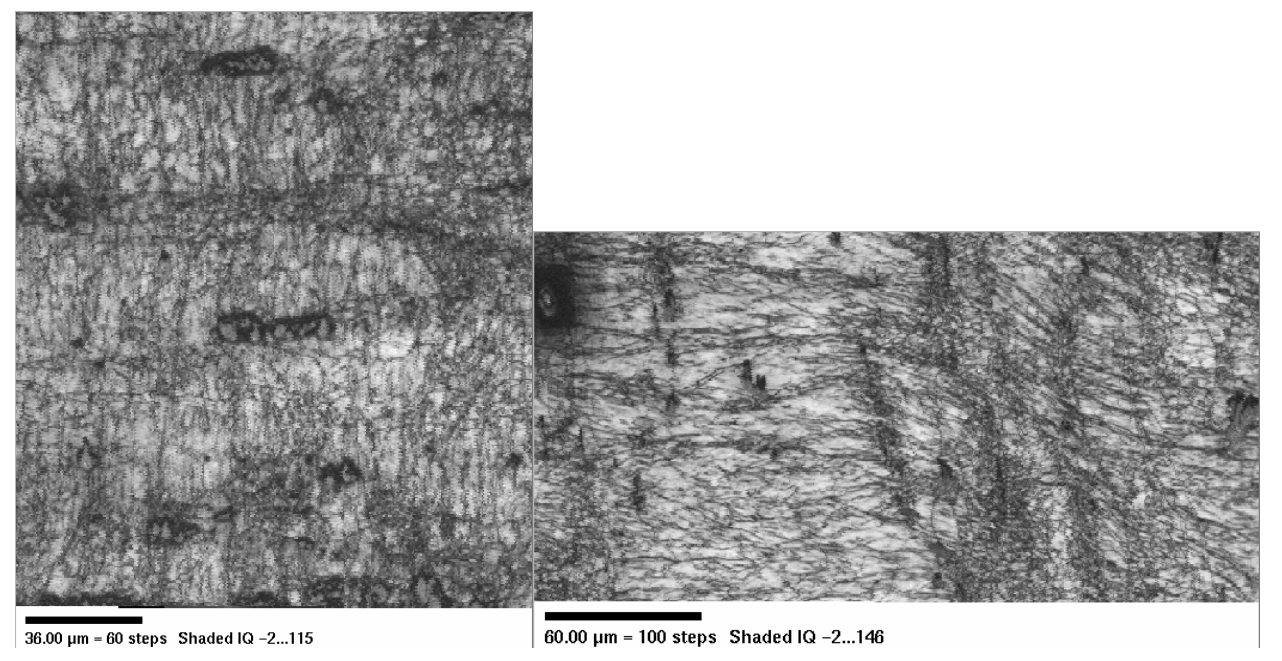

Fig 1.16: Image quality map of hot band in the RD/TD surface (left) and RD/TD mid-thickness (right) planes

These measurements indicate that the microtexture of the flash annealed material has some inhomogeneity on length scales greater than 200 microns. This inhomogeneity of the microtexture of the flashed annealed material may reflect an microtextural inhomogeneity in the as-rolled hot band or an inhomogeneity in the stringer distribution (e.g., the intermetallics and their distribution may be impacting the recovery and recrystallization during the flash annealing.

The dislocation and fine precipitate structures of both the as-rolled and flash annealed hot band have been investigated by TEM. As expected both the near-surface and midplane regions of the as-rolled material exhibit fine cell sizes ( $<2$ micron) and significant intercellular dislocation structure (dislocations and low angle walls). The flash annealed materials exhibited a large grain size consistent with recrystallization. However, a significant dislocation substructure that included dislocation dipoles and loops was present. This observation differs from the very low dislocation density observed in conventionally annealed materials and may reflect a difference in the recovery/recrystallization process in flash annealed material. There may be insufficient time during the rapid cool down to permit complete removal of the dislocation structure. 


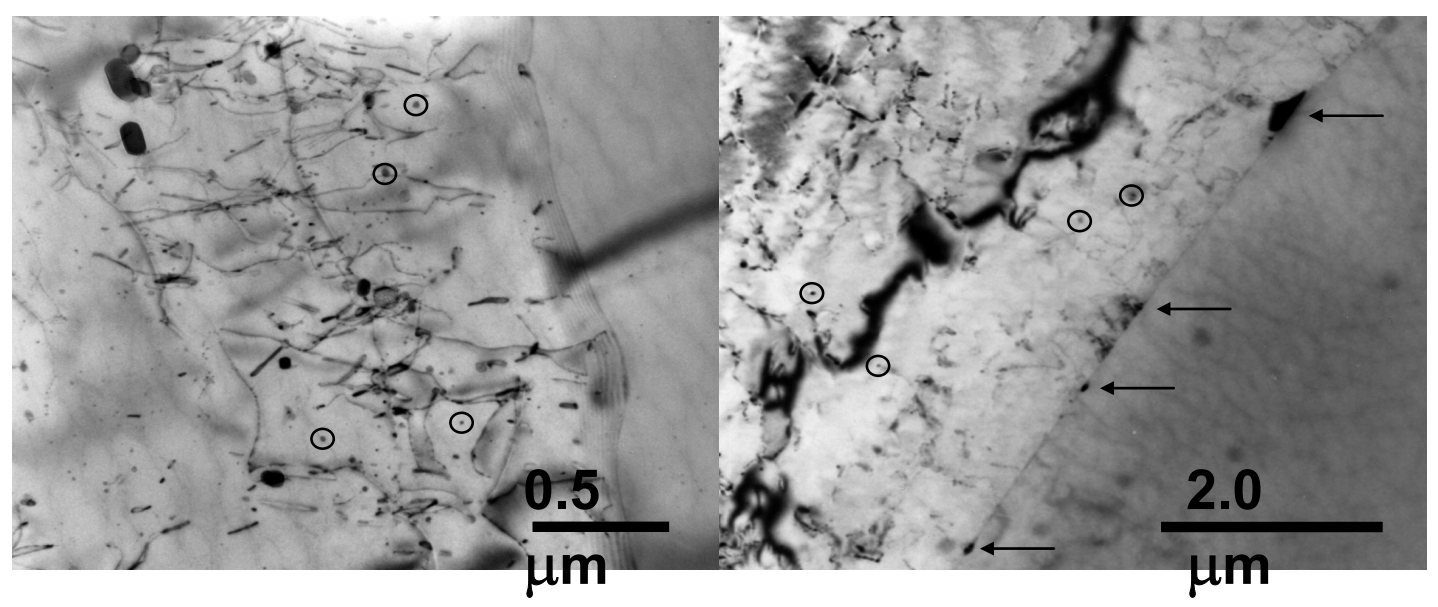

Fig 1.17: TEM images of 5754 hot band annealed at 900F, 1s at the RD-TD mid-thickness plane (left) and RD-TD surface plane (right). Arrows indicate GB precipitates and circles indicate some fine matrix precipitates. In the right image the elongated loop-like images are dislocation dipoles and loops

\subsection{3: Observations}

In general it was possible to obtain the good correlation between actual data and the model. The variations observed between the data and model could be explained by the process variations that normally occur at the plant level.

\section{4: University of Kentucky and Secat Inc}

\subsection{1: Introduction}

The University of Kentucky and Secat Inc focused on comparison of the properties of standard processed material with that of hot rolled in line anneal processed material. The tests were carried out in order to determine if in line hot rolled material would produce sheet material compared in performance to DC material used in the production of automotive grade material with similar properties.

Samples were received of two $5 \mathrm{xxx}$ alloys. In order to compare in-line annealed materials after different processing, sheets produced under different conditions of different thickness were received from Aleris produced by both the $\mathrm{DC}$ and $\mathrm{CC}$ manufacturing routes. The sheets were annealed by Aleris at different temperatures using in line anneal. In addition, the above hot bands were annealed in furnace, reduced in cold rolling and final annealing at Secat Inc. To compare with in-line annealed and normal annealed materials after different processing, tensile testing, bend testing, earing testing and Olsen testing were carried out in Secat, Inc. Studies were carried out to compare the material properties and microstructure. The photomicrographs of grain and particle structure as well as grain size and particle size distributions were obtained by optical microscopy and scan electronic microscopy (SEM).

The results of these tests are highly proprietary in nature and hence only the general results are reported. 


\subsection{2: Experimental Results}

Microstructure - All samples showed full recrystallization after in-line annealing and static annealing with smaller grains at surface than in the center layer in the sheets. With increase in inline annealing temperature, the mean grain size decreases

Particle structure - Particle structures from all samples also were studied along with particle area percent and particle size distributions. There are two types of particle composition in AA5754 and AA5052 alloys. They are mainly two types of particles $\boldsymbol{\alpha}$-AlMgSi and AlFe(Mn) particles.

Tensile - Ultimate tensile strength (UTS), Yield strength (YS), Elongation (EL), R-values and nvalues were measured in the $0^{\circ}$ directions (rolling direction, RD). In order to obtain similar tempers it was observed that the samples from in-line annealing and static annealing have different annealing temperatures.

Bend - All samples were successful bent to $180^{\circ}$ with the samples after in-line and static annealing have almost same bending rate.

Earing - In-line annealing shows variations in earing behavior but in general this should not be a constraint for processing by the end user. $\mathrm{g}$.

Olsen Testing - It was found that the samples after static annealing have higher Olsen values than ones after in-line annealing but this can be corrected by suitable alteration of anneal temperatures. The different final crystallization temperatures can obtain almost same Olsen values.

Hole Expansion - Hole expansion studies were carried out to try and determine the ease with each holes and similar forms could be created during fabrication. Results were similar on comparing material with similar properties.

\subsection{3: Observations and Summary}

1. All samples showed full recrystallization after in-line annealing and static annealing with smaller grains at surface than in the center layer in the sheets.

2. There are two types of particle composition in AA5754 and AA5052 alloys. They are mainly two types of particles $\boldsymbol{\alpha}$-AIMgSi and AlFe(Mn) particles.

3. All samples were successful bent to $180^{\circ}$ with the samples after in-line and static annealing have almost same bending rate.

4. In order to obtain similar tempers it was observed that the samples from in-line annealing and static annealing have different annealing temperatures.

5. In-line annealing shows variations in earing behavior but in general this should not be a constraint for processing by the end user.

6. It was found that the samples after static annealing have higher Olsen values than ones after in-line annealing but this can be corrected by suitable alteration of anneal temperatures. The different final crystallization temperatures can obtain almost same Olsen values. 
7. Hole expansion studies were carried out to try and determine the ease with each holes and similar forms could be created during fabrication. Results were similar on comparing material with similar properties.

\subsection{Cost Analysis}

A detailed techno-economic analysis was carried out in order to determine the feasibility of setting up an in line anneal facility in order to determine the profitability of such a unit.

The techno economic survey compared costs considering the use of anneal operation after hot roll under two circumstances - use of anneal furnaces vs. in line application immediately after hot roll. The basic data of output from the Haslett Caster was provided by Aleris and based on the output $/ \mathrm{hr}$ calculations were made regarding the no of annealing furnaces required, cost comparisons between standard anneal process and in line along with straight line 10 year capital depreciation along with building and support ancillaries, if applicable.

The net findings of the analysis indicate the following

- Lower equipment cost

- Less WIP inventory

- Less Building space

- Lower total capital cost

- Lower operating cost

The establishment of the in line annealing system makes economic sense with reasonable pay back period.

\subsection{Accomplishments}

\section{1: Technical Achievements}

\section{Design and build continuous in-line annealing equipment for plant-scale trials}

Prior to the project annealing was carried out as a batch type process. Based on process inputs from Aleris International CC facility and design by Ajax Magnethermic a continuous in line annealing equipment was designed and installed at Aleris International's Carson facility for carry out industrial size trails. This has resulted in knowledge on design and fabrication of in line annealing equipment for $\mathrm{CC}$.

Carry out plant-scale trials at Aleris International's facility in Carson, California.

Trials were carried out at the facility over a period of a week that was successfully able to produce in line annealed sheets for detailed material characterization and comparison of material properties vide the regular DC Casting process.

Optimize the processing variables utilizing a metallurgical model for the kinetics of microstructure and texture evolution during thermo-mechanical processing.

ORNL has carried out detailed work in the development of model that can be used to assist in predicting the kinetic of microstructure and texture evolution based on thermo mechanical processing. The model has been validated based on actual measurements carried out on material 
produced during the trials. The model is resident at Secat for use in interpretation of structures and its correlation to thermo mechanical processing steps.

Determine the effects of processing variables on the microstructure, texture, mechanical properties, and formability of aluminum sheet.

Detailed material characterization work was carried out with respect to tensile properties, formability, texture and microstructure. The studies proved that in line anneal can be utilized to produce sheet material with properties comparable to conventional CC cast products

\section{Develop design parameters for commercial implementation.}

Based on the successful conclusion of the trials design data has been generated that can be utilized for the construction of an inline anneal based plant either by retroactive fitment of the system or by the construction of a new plant at a Greenfield site.

\section{Conduct techno-economic studies of the recommended process equipment to identify impacts on production costs.}

Detailed techno-economic study has been carried out of the inline process as compared to existing process considering land, energy and capital investment. The savings are observed to be appreciable with respect to energy and hence cost/unit product produced.

\subsection{Technology Transfer}

Intellectual property has been generated from this significant research effort. The intellectual property includes: (1) the predictive microstructure model that can be used to assist in predicting microstructure behavior as related to different thermo mechanical processing techniques that is resident at Secat, Inc. and at ORNL and are accessible to the aluminum industry (2) Specific material property data on in line annealed material that is proprietary to Aleris International on $5 \mathrm{xxx}$ aluminum alloys (3) design data on in line anneal equipment. University of Kentucky and Secat research staff members have actively participated in the evaluation of material properties utilized in the modeling effort throughout the project period.

The basic model is available for use by the entire aluminum industry.

\subsection{Commercialization}

The project being proprietary in nature has resulted in information that can be used to set up a plant with low cost/unit product by Aleris International or licensed appropriately. Several patents are being processed in the regard by the industry partner in order to protect the relevant information. 


\section{Summary and Conclusions}

A successful project has been completed to understand the feasibility of using in line anneal technique to treat hot roll material as it emerges from the hot rolls. Design, erection and commissioning of a trial facility were successfully carried out at Aleris to produce sufficient amounts of material to evaluate material properties. Based on the successful conclusion of the trials design data has been generated that can be utilized for the construction of an inline anneal based plant either by retroactive fitment of the system or by the construction of a new plant at a Greenfield site.

During the course of the work it was proved that in line anneal can be utilized successfully to produce material comparable to DC cast material at much lower cost and meet the rigorous standards of the automotive industry.

A metallurgical model for the kinetics of microstructure and texture evolution during thermomechanical processing was developed and the model has been validated based on actual measurements carried out on material produced during the trials. The model is resident at Secat for use in interpretation of structures and its correlation to thermo mechanical processing steps.

Detailed material characterization work was carried out with respect to tensile properties, formability, texture and microstructure. The studies proved that in line anneal can be utilized to produce sheet material with properties comparable to conventional CC cast products

Based on the successful conclusion of the trials design data has been generated that can be utilized for the construction of an inline anneal based plant either by retroactive fitment of the system or by the construction of a new plant at a Greenfield site.

Detailed techno-economic study has been carried out of the inline process as compared to existing process considering land, energy and capital investment. The savings are observed to be appreciable with respect to energy and hence cost/unit product produced.

\section{Recommendations}

This research project has successfully demonstrated that the use of in line anneal in the continuous casting process can result in large savings in energy. Based on capital cost investment the industrial partner has to decide on an opportune time for making the necessary capital investments.

Full scale implementation of the proposed effort by the year 2015 could lead to yearly energy savings of 23 trillion Btu and related energy cost savings of $\$ 96$ million per year for the U. S. aluminum rolled products industry. 


\section{References}

1. 1S. Platek, "Commonwealth Aluminum state-of-the-art continuous casting," Light Metals 1999,: Proceedings of Sessions, TMS Annual Meeting (Warrendale, PA) Feb. 28-Mar 4, 1999, TMS, pp. 939-944

2. "Aluminum Industry Technology Roadmap," The Aluminum Association, 1997.

3. D.G. Altenpohl, "Aluminum: Technology Applications, Applications, and Environment," TMS, The Aluminum Association, Warrendale, PA/Washington, DC, 1998, pp 86-94.

4. W. Szczypiorski W and R. Szczypiorsk, "Mechanical and metallurgical characteristics of twin-belt cast aluminum strip using current Hazelett technology," Proceedings of the $120^{\text {th }}$ TMS Annual Meeting, TMS 1991, pp.805-814

5. 1999 Annual Progress Report, Vehicle Systems Team, Lightweight Vehicle Systems Materials, U.S. Department of Energy, pp. 9-11.

6. E.A. Kenik, "Spatial Resolution of Electron Backscatter Diffraction in a FEG-SEM," in Proc. Microscopy and Microanalysis 1996 (Proc. 54th Ann. Meet. Microscopy Soc. Amer.), eds. G.W. Bailey et al., San Francisco Press, San Francisco, CA (1996) pp. 348-9.

7. J.W. Sinclair, K.T. Hartwig Jr., R.E. Goforth, E.A. Kenik, and E. Voelk1, "Microstructure and Mechanical Properties of Aluminum 5083 Processed by Equal Channel Angular Extrusion," pp. 393-403 in Ultrafine Grained Materials, eds. R.S. Mishra et al., TMS, Warrendale, PA (2000).

8. "Monte Carlo Simulation of Deformation Substructure Evolution during Recrystallization," B. Radhakrishnan, G. Sarma and T. Zacharia, submitted to Scripta Materialia, vol.39, pp. 1639-1645, 1998.

9. "Finite Element Simulations of Cold Deformation at the Mesoscale," G. B. Sarma, B. Radhakrishnan and T. Zacharia, submitted to Computational Materials Science., vol. 12, pp. 105-123, 1998.

10. Zhong Li, Letter to

11. Zhong Li, Letter to , dated

12. Hazelett Strip Casting Corporation, on-line product information from http://www.hazelett.com

13. Kirk-Othmer, Encyclopedia of Chemical Technology, Fourth Edition, Volume 2, John Wiley \& Sons, New York, p 196.

14. Metal Statistics 1998, American Metal Market, New York, 1998, p. 114.

15. Peter Regan, Hazelett Strip Casting Corporation, private communication, January 17, 2006.

i W. Szczypiorski W and R. Szczypiorsk, "Mechanical and metallurgical characteristics of twinbelt cast aluminum strip using current Hazelett technology," Proceedings of the $120^{\text {th }}$ TMS Annual Meeting, TMS 1991, pp.805-814

ii 1999 Annual Progress Report, Vehicle Systems Team, Lightweight Vehicle Systems Materials, U.S. Department of Energy, pp. 9-11.

iii "Monte Carlo Simulation of Deformation Substructure Evolution during Recrystallization," B. Radhakrishnan, G. Sarma and T. Zacharia, submitted to Scripta Materialia, vol.39, pp. 1639$1645,1998$.

iv "Finite Element Simulations of Cold Deformation at the Mesoscale," G. B. Sarma, B. Radhakrishnan and T. Zacharia, submitted to Computational Materials Science., vol. 12, pp. 105123, 1998. 


\subsection{Publications}

Due to confidential nature of the work done no direct publications resulted from the projects. A few related publications are given blow.

1) Zhao, Y. M., Liu, W.C. and Morris, J.G. (2004, November). Quantitative analysis of texture evolution of cold-rolled direct-chill-cast and continuous-cast AA5052 and A5182 aluminum alloys during isothermal annealing. Metallurgical and Materials Transactions A. 35A.11, 3613-3629A.

2) Zhao, Y.M., Wen, W. and Morris, J.G. (2004, May 25). The differences in particle structures and recrystallization behaviors between DC and CC AA5052 aluminum alloys. Materials Science and Engineering A. 373.1-2, 167-174

3) Liu, W.C. and Morris, J.G. (2004, January). Quantitative analysis of texture evolution in cold-rolled, continuous-cast AA $5 \times x x$-series aluminum alloys. Metallurgical And Materials Transactions A. 35A.1, 265-277A.

4) Zhao, Y.M., Liu, W.C. and Morris, J.C. (2003, October). Comparison of texture evolution during cold rolling between direct chill and continuous cast aluminum alloy 5052. Materials Science and Technology. 19.10, 1379-1385. 